\title{
Recycled concrete with coarse recycled aggregate. An overview and analysis
}

\author{
B. González-Fonteboa ${ }^{\mathrm{a}} \bowtie$, S. Seara-Paz ${ }^{\mathrm{b}}$, J. de Brito ${ }^{\mathrm{c}}$, I. González-Taboada ${ }^{\mathrm{a}}$, F. Martínez-Abella ${ }^{\mathrm{a}}$, \\ R. Vasco-Silva ${ }^{\mathrm{d}}$ \\ a. Department of Civil Engineering, Civil Engineering School, University of A Coruña, (A Coruña, Spain) \\ b. Department of Civil Engineering, School of Building Engineering. University of A Coruña. (A Coruña, Spain) \\ c. CERis/ICIST, Instituto Superior Técnico, University of Lisbon (Lisbon, Portugal) \\ d. CERis/ICIST, DECivil Instituto Superior Técnico, University of Lisbon (Lisbon, Portugal) \\ \bfonteboa@udc.es
}

\begin{abstract}
The construction field has contributed to environmental degradation, producing a high amount of construction and demolition waste (C\&D waste) and consuming large volumes of natural resources. In this context, recycled concrete $(\mathrm{RC})$ has been recognised as a means to preserve natural resources and reduce space for waste storage. During the last decades, many researchers have developed works studying different recycled concrete properties.

This review focuses on structural RC made with coarse recycled aggregate from concrete waste. The main objective is to provide a state of the art report on RC's properties and an analysis on how to predict them taking into account relevant research works. Moreover, the study tries to collect and update RC findings, proposing equations to define RC's performance, in terms of mechanical strength, modulus of elasticity, stress-strain, creep and shrinkage.
\end{abstract}

KEY WORDS: Recycled concrete; Mechanical properties; Deformation; Shrinkage; Durability.

Citation/Citar como: González-Fonteboa, B.; Seara-Paz, S.; de Brito, J.; González-Taboada, I.; Martínez-Abella, F.; Vasco-Silva, R. (2018) Recycled concrete with coarse recycled aggregate. An overview and analysis. Mater. Construcc. 68 [330], e151. https://doi.org/10.3989/mc.2018.13317

RESUMEN: Hormigón reciclado con árido grueso reciclado. Una visión general y análisis. El campo de la construcción ha contribuido a la degradación del medio ambiente, produciendo gran cantidad de residuos de construcción y demolición y consumiendo grandes volúmenes de recursos naturales. En este contexto, el hormigón reciclado se ha presentado como una opción para preservar los recursos naturales y reducir el espacio destinado a vertedero. Así, durante las últimas décadas, muchos investigadores han desarrollado trabajos para estudiar las propiedades del hormigón reciclado.

Este artículo se centra en el hormigón estructural fabricado con árido reciclado grueso procedente de residuos de hormigón. El principal objetivo es desarrollar un estado del arte que recoja las principales propiedades del hormigón reciclado y un análisis de cómo calcularlas teniendo en cuenta un gran número de trabajos relevantes en este ámbito. Adicionalmente, el estudio recopila y actualiza el conocimiento sobre estos hormigones, proponiendo ecuaciones que permitan definir sus resistencias mecánicas, módulo de elasticidad, tensión-deformación, fluencia y retracción.

Palabras clave: Hormigón reciclado; Propiedades mecánicas; Deformación; Retracción; Durabilidad.

ORCID ID: B. González-Fonteboa (http://orcid.org/0000-0002-8856-2002); S. Seara-Paz (http://orcid.org/00000001-6565-0299); J. de Brito (http://orcid.org/0000-0001-6766-2736); I. González-Taboada (http://orcid.org/00000001-7992-4713); F. Martínez-Abella (http://orcid.org/0000-0002-5991-6414); R. Vasco-Silva (http://orcid. org/0000-0002-2276-9721).

Copyright: (C) 2018 CSIC. This is an open-access article distributed under the terms of the Creative Commons Attribution 4.0 International (CC BY 4.0) License. 


\section{INTRODUCTION AND OBJECTIVES}

Scientific studies reveal that some climate changes are inevitable, becoming one of the main global threats we must face in this century. The United Nations established a new universal set of goals that all member states will be expected to use to outline their political policies over the next 15 years in order to ensure a sustainable development (1). These objectives include, but are not limited to, the suitable management of seas, oceans and forests in order to conserve natural resources and reverse land degradation.

The construction field has also contributed to environmental degradation, producing a high amount of construction and demolition waste (C\&D waste) and consuming large volumes of natural resources. In this context, recycled concrete (RC) has been recognised as a means to preserve natural resources and reduce space for waste storage (2). However, the use of this concrete is not yet widespread despite the great number of studies involving RC's behaviour and the establishment of trustworthy design guidelines (2-8). This matter is especially important for those countries whose codes and standards do not include recommendations for high replacement ratios.

In order to produce RC, it is necessary to know the influence of the recycled aggregate's content and quality, which is usually determined by the aggregate's composition, water absorption capacity and attached mortar content (made of the source concrete) (9-15). These parameters lead to different sorts of recycled aggregates: recycled concrete aggregates (RCA), recycled ceramic aggregates or mixed recycled aggregates.

Recycled aggregate from concrete waste is the most suitable aggregate to produce structural RC due to its favourable characteristics. In this case, the presence of impurities is low, where the adhered mortar is the key parameter that controls the recycled aggregate's quality, which is also linked to the characteristics of the source concrete. Low-grade source concrete leads to low-grade adhered mortar and, consequently, worse recycled aggregate. Secondly, the recycling process is also important because it influences the amount of attached mortar, which decreases as the stages in the crushing process increase (16). However, ceramic and mix recycled aggregates are mostly defined by the quantity of impurities rather than by the adhered mortar.

It is widely accepted that a higher amount of adhered mortar leads to higher water absorption capacity that largely modifies the recycled concrete's properties. Therefore, one of the best procedures to define the recycled aggregate's quality is to measure its water absorption capacity. In this regard, coarse RCA presents a water absorption capacity under $8.5 \%(9)$. This value increases when recycled fine aggregate is analysed. In fact, the recommendations to produce structural RC propose the use of coarse recycled aggregate only. However, recent studies (17) have provided further information about fine RCA to promote its use in $\mathrm{RC}$.

This review focuses on structural RC made with coarse RCA. The main objective is to provide a state of the art report on RC's properties and an analysis on how to predict them taking into account relevant research works. This study tries to collect and update $\mathrm{RC}$ findings, proposing equations to define RC's performance, in terms of mechanical strength, modulus of elasticity, stress-strain, creep and shrinkage.

\section{MECHANICAL STRENGTHS}

RC's properties are influenced by the quality of new and old interfacial transition zones (ITZ). The new ITZ is located between the old adhered mortar and the new mortar matrix (Figure 1 (20)) and the old ITZ is that between the original aggregate and the old adhered mortar (old ITZ). Concrete properties are usually influenced by the weakest on $(18,19)$.

The strength characteristics of RC depend on the quality of new ITZ when the quality of old ITZ is better than that of new ITZ. On the other hand, they depend on the quality of old ITZ, when the quality of new ITZ is better than that of old ITZ (21).

Moreover, for a given water to cement (w/c) ratio, there will be a higher strength loss as the quality of recycled aggregate worsens. This effect is more noticeable for lower w/c ratios since the ultimate compressive strength becomes more dependent on the strength of recycled aggregate, instead of that of the cement matrix (22).

In terms of the morphological characteristics of the aggregates used to produce RC, it was found that the strength performance is different when rounded or crushed natural aggregates are used. The former may not show a decrease in the compressive

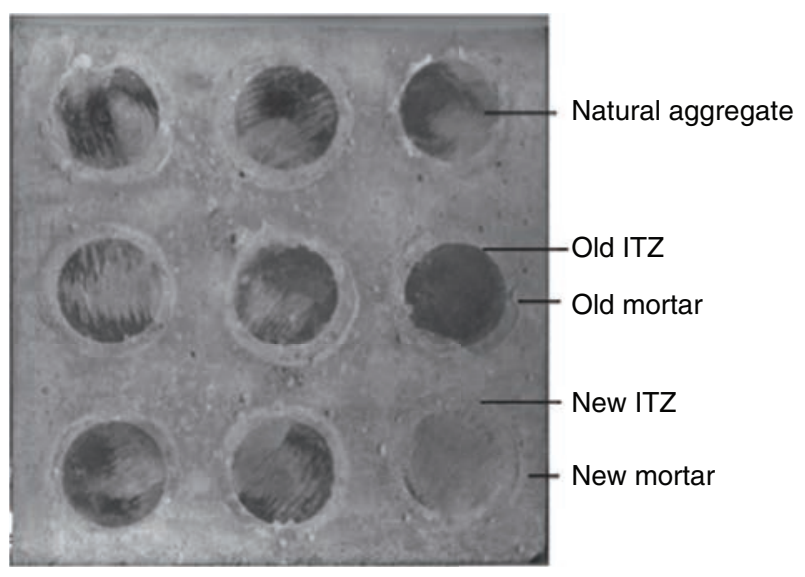

FIGURE 1. The RC's interfacial transition zones (ITZ) (20). 
strength, and they may even produce an increase of up to $15 \%(23)$.

\subsection{Compressive strength $\left(\mathbf{f}_{\mathrm{c}}\right)$}

In general, RC's compressive strength is lower than that of conventional concrete, decreasing when the coarse aggregate incorporation ratio increases $(2,24-27)$. However, the extent of this decrease mainly depends on the recycled aggregate's content, concrete production method (9) and recycled aggregates' type, size and origin (22).

It is clear that the compressive strength of $\mathrm{RC}$ is lower than the strength of reference concrete, made with natural aggregate. In general, the recycled aggregate's quality influences concrete properties in different ways. For a given w/c ratio, strength loss increases as the quality of the recycled aggregate worsens. However, this effect is more noticeable for lower w/c ratios since the ultimate compressive strength becomes more dependent on the strength of the recycled aggregate, instead of the cement matrix (22).

Using the database of González-Taboada et al. (9), Figure 2 analyses the relationship "RC's compressive strength vs conventional concrete's compressive strength" taking into account different ratios of coarse RCA. 229, 80 and 75 mixes were used in the case of $100 \%, 50 \%$ and $20 \%$ replacements ratios, respectively.

This figure confirms that the recycled aggregate ratio influences the strength loss. The lower the coarse RCA content is, the lower the strength loss will be. The square of the Pearson product-moment correlation coefficient (coefficient of determination, $\mathrm{R}^{2}$ ) has been calculated. In all cases the value
$\mathrm{R}^{2}$ is between 0.9 and 1 , what means that there is a very strong correlation.

Low replacement ratios $(20 \%)$ hardly influence the compressive strength of concrete. According to Figure 2, average reductions were 5\%,10\% and $13 \%$ for $20 \%, 50 \%$ and $100 \%$ replacement ratios respectively.

Xiao et al. (28) investigated the statistical characteristics of the compressive strength of $\mathrm{RC}$ with relatively uniform quality. It is found that a normal distribution model can be applied to fit the compressive strength results of the RC at a 95\% confidence level with different coarse RCA contents (Figure 3). Researchers from other countries (29) also prove that the coefficient of variation for compressive strength of RAC in the laboratory is not much different from that of conventional concrete when the same coarse RCA was used throughout the production.

Xiao et al. (28) concluded that further research is required in terms of statistical characteristics of the compressive strength of concrete with recycled aggregate from different resources. The test results reveal that the recycled aggregate with non-uniform quality increases the scatter of the compressive strength of RC but the normal model can still be used to describe its probability distribution. However, the coefficient of variation for compressive strength is slightly larger.

This conclusion has also been achieved by Rahal (30), who found similar coefficients of variation in recycled and conventional concrete and explained that this difference is insignificant and possibly due to the limited number of sources of the recycled aggregate.

Different authors $(31,32)$ analysed the relationship between the cube compressive strength $\left(f_{\mathrm{cu}}\right)$

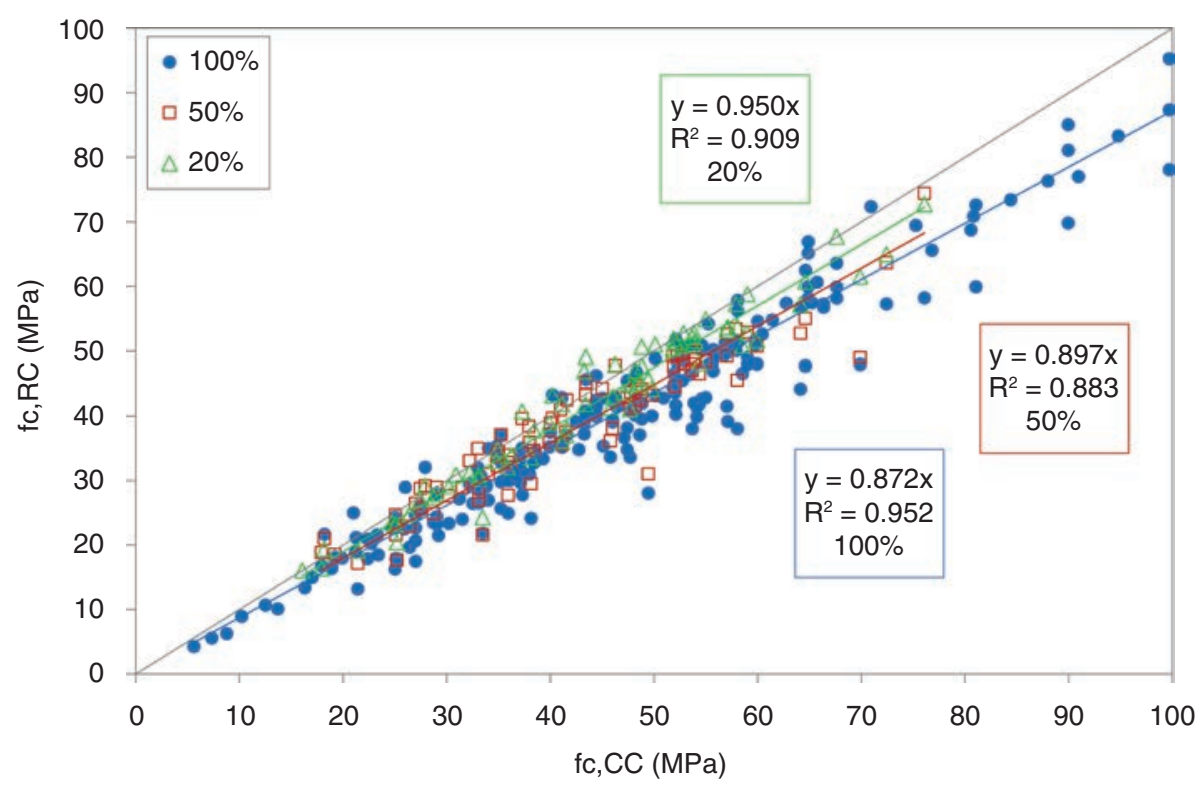

FIGURE 2. $f_{c, c c} v s . f_{c, R C}$. 


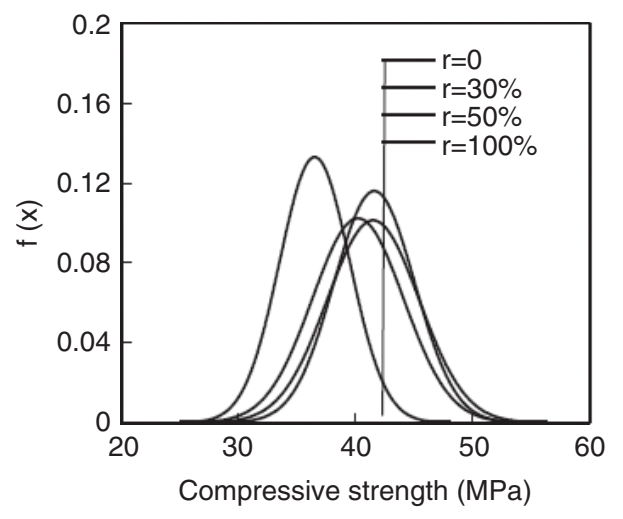

(a) Normal distribution model

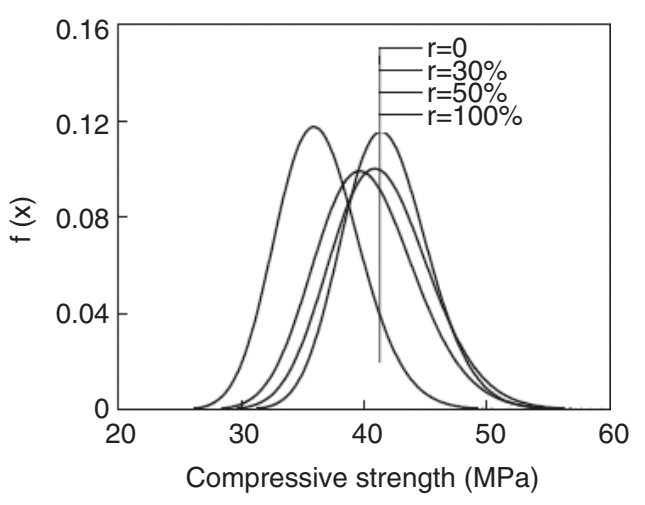

(b) Lognormal distribution model

FIGURE 3. Distribution model for compressive strength of RC (28).

and the cylinder compressive strength $\left(f_{\text {cyl }}\right)$. Li (33) carried out an extensive experimental study of concrete with $100 \%$ recycled aggregate only. The cylinder compressive strength was determined on cylindrical specimens of $150 \mathrm{~mm}(\varnothing) \times 300 \mathrm{~mm}$. The test results indicate that a linear relation exists between the cylinder and the cube compressive strengths [Eq. 1]. It should be noted that [Eq. 1] is only valid up to cube compressive strength of about $45 \mathrm{MPa}$.

$$
f_{c y l}=0.82 f_{c u}
$$

Zhou et al. (34) also analysed the relationship cube compressive strength/axial compressive strength of RC. They concluded that equations adopted by codes for conventional concrete are not applicable to RC. As a result, they suggest a regression equation based on the experimental results in order to obtain the compressive strength of $\mathrm{RC}\left(\mathrm{f}_{\mathrm{cy}}\right)$ through the cube compressive strength $\left(\mathrm{f}_{\mathrm{cu}}\right)$ and taking into account the incorporation ratio of coarse recycled aggregate $(r, 0 \leq r \leq 1)$, [Eq. 2]:

$$
f_{c y l}=\left(a r^{2}+b r+c\right) \times 0.89 f_{c u}
$$

For recycled aggregates obtained from crushed concrete waste, a is $0.0227, \mathrm{~b}$ is 0.1030 and $\mathrm{c}$ is 0.9620 .

In order to confirm this result, the ratio $f_{\text {cyl }}$ to $\mathrm{f}_{\mathrm{cu}}$ was calculated using the database of GonzálezTaboada et al. (9) with some researcher works that provide both results. Applying regression analysis, and analysing the results taking into account different replacement ratios, $0-20 \%$ and $50-100 \%$, the ratio was found to be 0.810 and 0.861 respectively (Figure 4).
Finally, over a long period of time, some authors observed that RC may show greater strength development than the corresponding conventional concrete. This was explained by the latent cementitious properties of the mortar adhered to the original aggregates $(22,35)$.

Eiras et al. (35) studied the compressive strength at 3, 7, 90 and 365 days. In order to know the influence of the coarse RCA on this property, the relative strength was calculated using the compressive strength at different ages $\left(f_{c, t}\right)$ relative to that obtained at 28 days $\left(\mathrm{f}_{\mathrm{c}, 28}\right)$ (Figure 5).

These authors proposed an equation for their particular results. Taking it as a reference and using the database of González-Taboada et al. (9), the following equation was obtained to predict RC's compressive strength at different ages [Eq. 3].

$f_{c, t, R C}=f_{c, t, C O D E} \cdot e^{\left[(0.0176 \cdot r) \cdot\left(1-\left(\frac{28}{t}\right)^{(1.4766-0.3058 \cdot r)}\right)\right]}$

The new expression was adjusted using multivariable regression and with a Pearson correlation coefficient of 0.8811 , confirming its suitability.

According to Figure 5, RC presents a different development of compressive strength from conventional ones. At 3 and 7 days, a delay in the development of compressive strengths of RC relative to conventional concrete can be seen. At 90 and 365 days, there are no significant differences between the development of compressive strength of $\mathrm{RC}$ and conventional concrete.

These differences are attributed to the use of recycled aggregate under pre-saturated conditions or with an extra quantity of water is added during mixing. This produces a curing effect in $\mathrm{RC}$ at early ages. For this reason, it has been named by other authors as "internal curing" $(21,36)$. The extra water inside the pores of recycled aggregates bleeds to cement paste during the hydration process resulting in a weaker interfacial transition zone. This results 


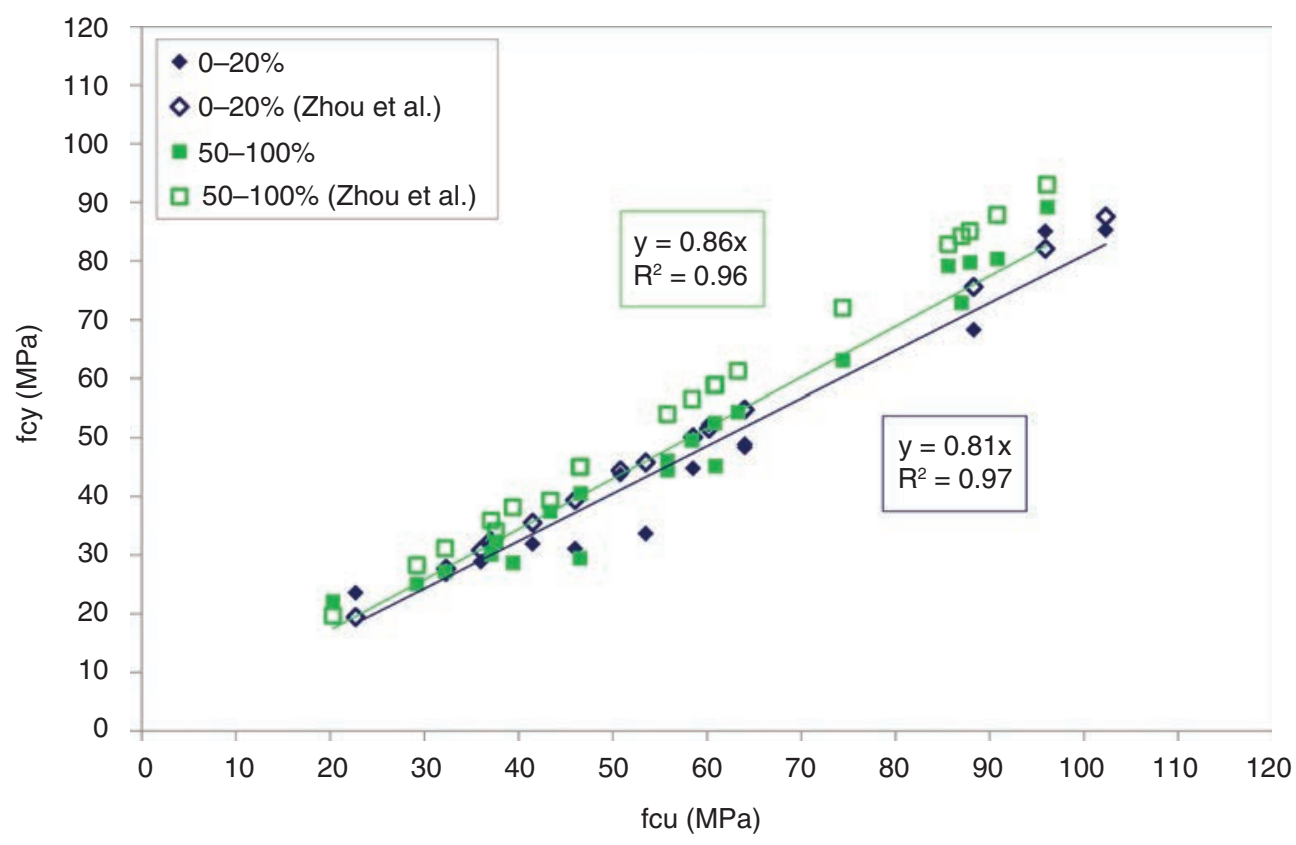

FIGURE 4. $f_{c u}$ vs. $f_{c y l}$.

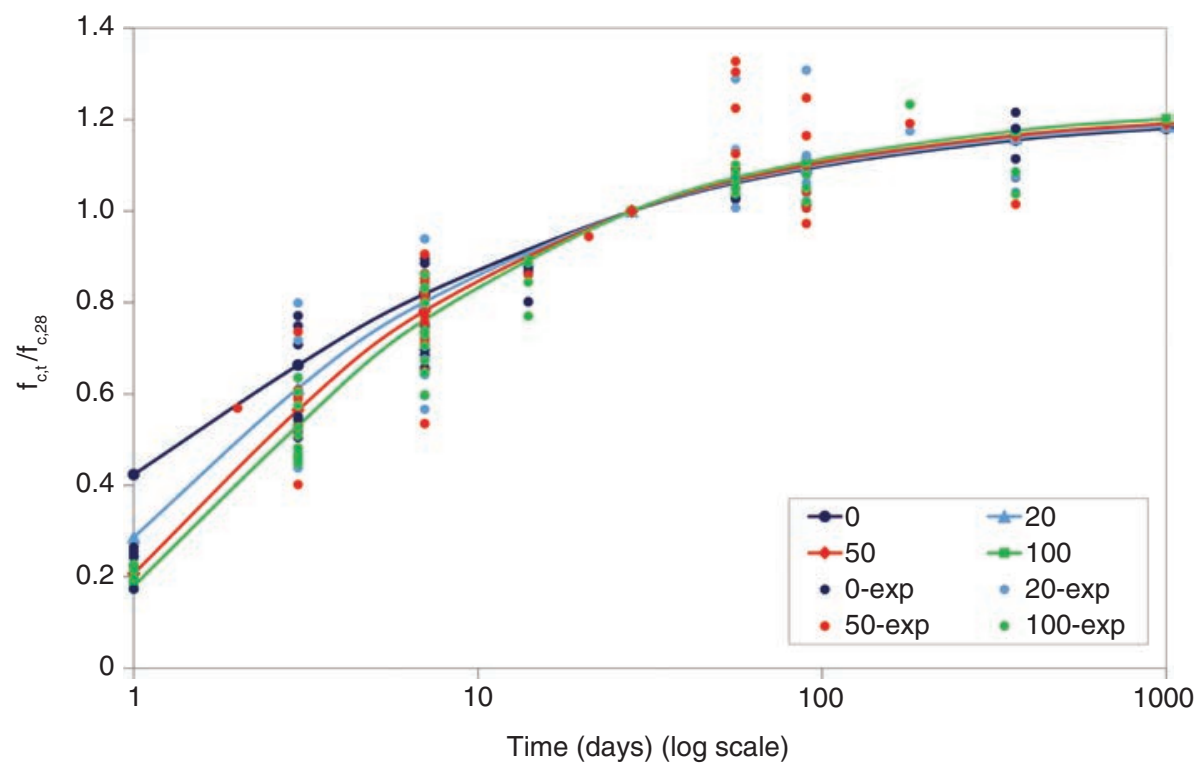

FIGURE 5. $f_{\mathrm{c}}(t) / f_{\mathrm{c}}(28)$ at different ages. Experimental (9) and proposal.

in a different development of compressive strength between recycled and conventional concretes, especially significant at early ages $(6,21,35,36)$.

\subsection{Splitting tensile strength $\left(\mathbf{f}_{\mathrm{sp}}\right)$}

There are several interesting works $(22,37)$ that have tried to predict the splitting tensile strength of recycled aggregate concretes. These authors have also analysed the scatter of the test results for this property in different campaigns. The decrease in splitting tensile strength was found to be up to $10 \%$ (38). Moreover, when RC is produced with crushed conventional aggregates, some researchers have obtained a decrease of $5-15 \%$ for a $50 \%$ replacement ratio and of $15-25 \%$ for $100 \%$ (37). However, no significant differences were observed when rounded natural aggregates are used.

Recently, Silva et al. (39) suggested that the tensile strength is also affected, as compressive strength (22), by the recycled aggregate's content, size, type and quality. They concluded that the incorporation 
of recycled aggregates causes a proportional decrease in tensile strength, at a rate that follows the same relationship as observed in conventional concrete. However, in a few cases RC exhibited similar or even slightly greater strength. It is possible that the bond strength in the ITZ, between the old adhered mortar and new cement paste, improved due to the rough nature of coarse RCA (40).

In addition, several past investigations on RC showed that the effect of recycled aggregate content on splitting tensile strength is lower than on compressive strength $(33,41-43)$.

Using the database of González-Taboada et al. (9), Figure 6 shows the relationship between RC and conventional concrete's splitting tensile strength for different replacement ratios, 50-100\% (106 mixes) and $<50 \%$ (38 mixes). According to Figure 6, the average reductions were $7 \%$ and $10 \%$ for low and high replacement ratios, respectively.
Some authors suggest that the equations proposed by codes and standards to predict splitting tensile strength as a function of compressive strength are not suitable when RC is used. In this way, these authors $(33,44,45)$, based on their experimental campaigns, have proposed specific expressions adjusted to predict the RC's splitting tensile strength (Table 1).

In this work, using multivariable regression and the database of González-Taboada et al. (9), an equation to predict the structural RC's splitting tensile strength has been developed (Table 1). It is based on the Eurocode equation, although introducing the replacement ratio and the coarse RCA's quality (considering its water absorption). The equation obtained with multivariable regression shows a Pearson correlation coefficient of 0.85 .

The results obtained with the proposed equation are shown in Figure 7 comparing them with the equations proposed by other authors.

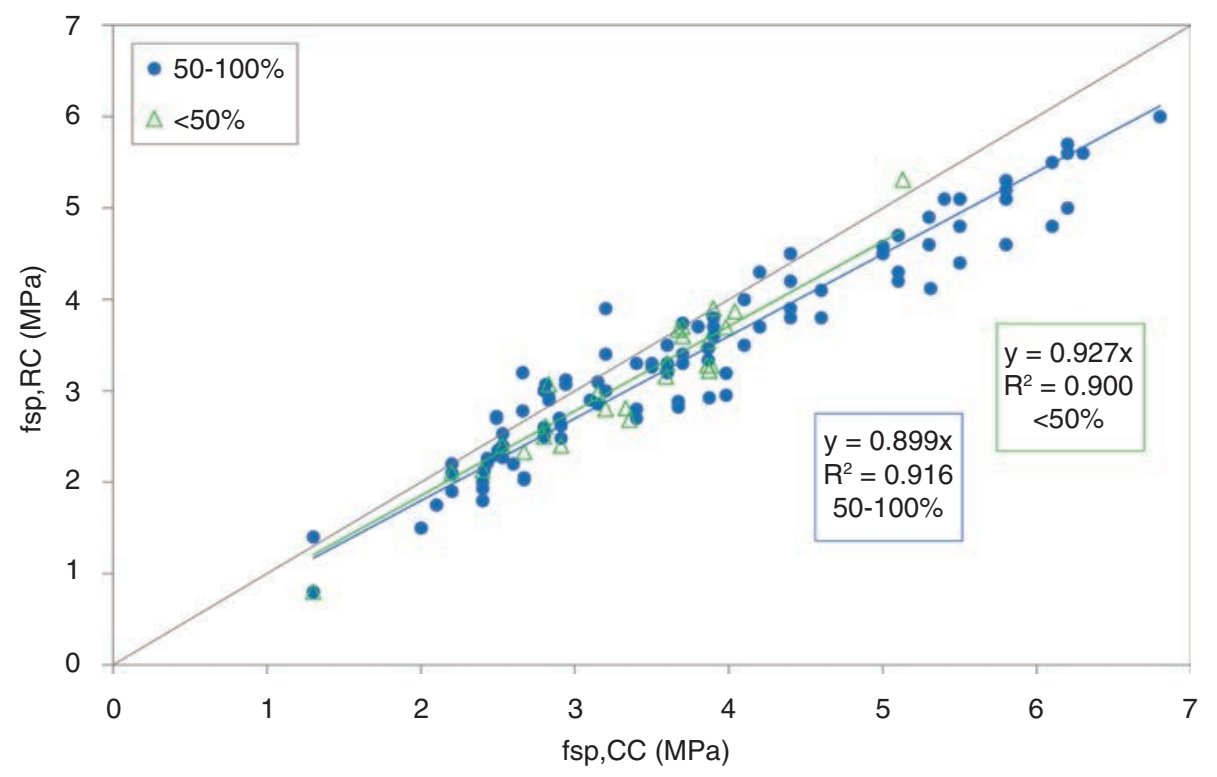

FiguRE 6. $f_{s p, C C} v s . f_{s p, R C}$.

TABLE 1. Authors' equations $-f_{s p, R C}$

\begin{tabular}{ll}
\hline Reference & \multicolumn{1}{c}{ Equation } \\
\hline Proposal & $f_{s p, R C}=\frac{\left(1-0.086 \cdot r \cdot \frac{W A}{5}\right)}{(1-0.605 \cdot r)} \cdot f_{s p, C O D E}^{(1-0.465 \cdot r)}$ \\
Li et al. (2008) (46) & $f_{t}=(0.24-0.06 \cdot r) \cdot f_{c u}^{2 / 3}$ \\
Xiao et al. (2006) (44) & $f_{s p}=0.24 \cdot f_{c u}^{0.65}$ \\
Katz (2003) (45) & $f_{s p}=0.59 \cdot \sqrt{f_{c}}$ \\
\hline
\end{tabular}




\subsection{Flexural strength $\left(f_{c f}\right)$}

The flexural strength of $\mathrm{RC}$ was found to slightly decrease with higher replacement levels of recycled aggregate. On the one hand, this is due to the reduced bond performance of the interfacial transition zone at the residual and new mortar interface. Another reason is the reduction in particle interlocking with the increased residual mortar content (47).

It was found that the flexural strength of $\mathrm{RC}$ can decrease up to $10 \%(48,49)$. However, some authors reported that there was no significant difference in the flexural strength of RC even with $100 \%$ recycled aggregate relative to that of conventional concrete (50). At different w/c ratios, Bairagi et al. (51) observed more differences in the flexural strength of $\mathrm{RC}$ than in conventional concrete.

\section{MODULUS OF ELASTICITY $\left(\mathrm{E}_{\mathrm{C}}\right)$}

Concrete's elasticity modulus is related to the aggregates and cement's paste's rigidity. The cement paste modulus is lower than that of the aggregates and also lower than that of concrete (52). The replacement of natural aggregate with recycled aggregate also affects the modulus of elasticity. The content of recycled aggregate has more effect on the modulus of elasticity than on compressive strength due to its porous nature, low density and weak bond between old ITZ and new ITZ.

Therefore, recycled aggregates (with adhered mortar) present a modulus of elasticity lower than natural aggregates and RC's modulus will be lower than that of conventional concrete $(53,54)$. The new interfaces' weakness (new cement mortar-aggregate, old cement mortar-aggregate and old cement mortar-new cement mortar) can lead to the presence of more capillary voids and a progressive development of cracks, which will affect the concrete's deformability (51).

It is clear that RC's modulus is lower than that of conventional concrete. It was found that the modulus of elasticity of recycled concrete with $100 \%$ recycled aggregate can be lowered up to $45 \%$ relative to that of natural aggregate concrete (58). This will be an upper limit since many authors in their studies have obtained lower reductions $(22,23,55)$.

Using the database of González-Taboada et al. (9), Figure 8 shows the relationship between recycled and conventional concrete modulus for different replacement ratios, $50-100 \%$ (128 mixes) and $<50 \%$ (58 mixes). It can be seen that the lower the recycled aggregate ratio the lower the modulus loss. According to Figure 8, the average reductions were $11 \%$ and $17 \%$ for low and high replacement ratios respectively.

Most of the codes and standards suggest equations to predict the modulus of elasticity as a function of compressive strength. These expressions are not suitable when RC is used and many authors have proposed different expressions to predict it (Table 2) $(31,37,38)$. However, these expressions have been adjusted to the authors' specific results and they present some scatter when other researchers' results are analysed.

Duan et al. (31) have explored the applicability of artificial neural networks (ANN) in modelling the recycled aggregate concrete's modulus. Their results show that the constructed ANN models can accurately predict the elastic modulus of concrete made with recycled aggregates derived from different sources. Won-Jun Park et al. (32) with more than

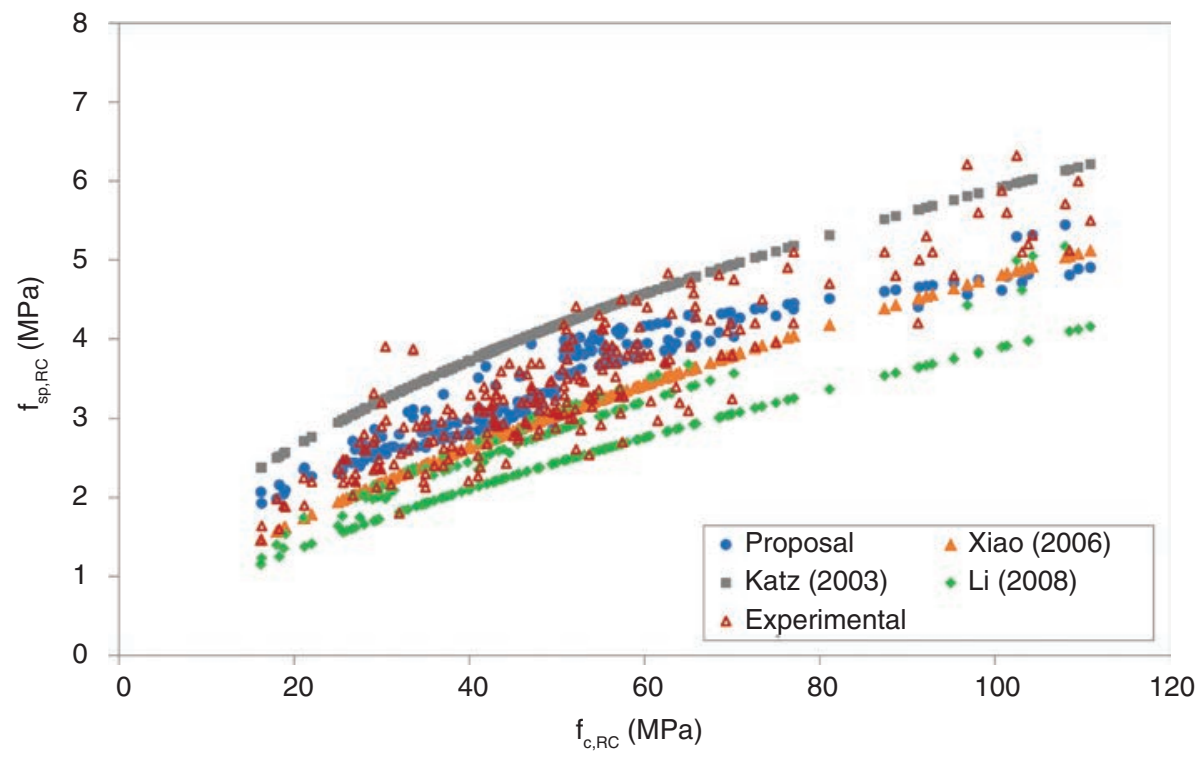

FIGURE 7. Experimental and authors' equations of $f_{s p, R C}$. 
8 B. González-Fonteboa et al.

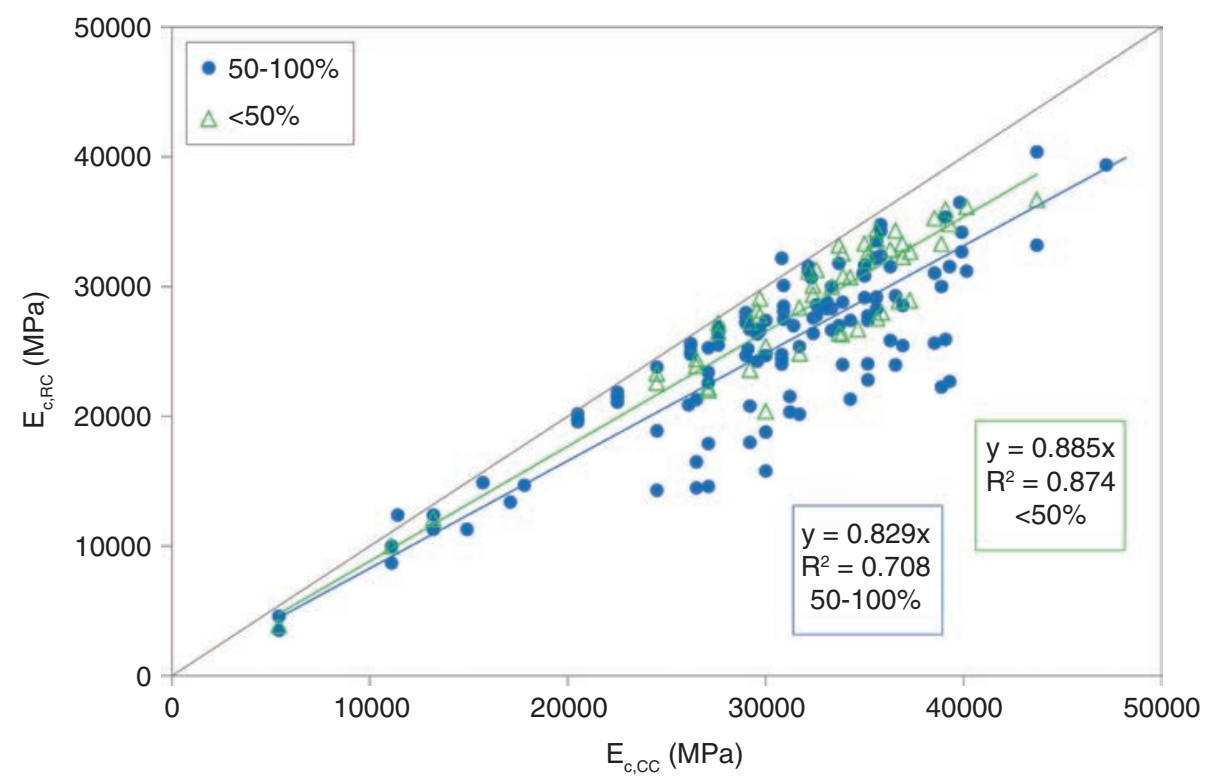

FiguRE 8. $E_{c, C C}$ vs. $E_{c, R C}$.

TABLE 2. Authors' equations $-E_{R C}$

\begin{tabular}{|c|c|}
\hline Reference & Equation \\
\hline Proposal & $E_{R C}=\frac{\left(1+0.049 \cdot r \cdot \frac{W A}{5}\right)}{(1+0.858 \cdot r)} \cdot\left(E_{C, C O D E}\right)^{(1+0.726 \cdot r)}$ \\
\hline González-Fonteboa et al. (2011) (43) & $E_{c}=(1-0.0020 \cdot r) \cdot 22000 \cdot\left(\frac{f_{c m}}{10}\right)^{0.3}$ \\
\hline Corinaldesi (2010) (56) a & $E_{c}=18800 \cdot \sqrt[3]{\frac{0.83 \cdot f_{c u}}{10}}$ \\
\hline Corinaldesi and Moriconi (2010) (56) b & $E_{c}=909 \cdot f_{c u}+8738$ \\
\hline Tangchirapat et al. (2010) (57) & $E_{c}=4450 \cdot f_{c}^{0.5}$ \\
\hline Li et al. (2008) (46) & $E_{c}=5.5 \cdot 10^{3} \cdot f_{c}^{0.5} \cdot\left(\frac{\rho}{2400}\right) \cdot\left(1-\frac{r}{\alpha}\right)$ \\
\hline & $\alpha=2.2876 \cdot r+0.1288$ \\
\hline Xiao et al. (2006) (44) & $E_{c}=\frac{10^{5}}{2.8+\frac{40.1}{f_{c}}}$ \\
\hline Katz (2003) (45) & $E_{c}=0.043 \cdot \rho^{1.5} \cdot f_{c}^{0.5}$ \\
\hline Zilch and Roos (2001) (58) & $E_{c}=9100 \cdot\left(f_{c}+8\right)^{1 / 3} \cdot\left(\frac{\rho}{2400}\right)^{2}$ \\
\hline Dhir et al. (1999) (59) & $E_{c}=370 \cdot f_{c}+13100$ \\
\hline Mellmann (1999) (60) & $E_{c}=378 \cdot f_{c}+8242$ \\
\hline
\end{tabular}


TABLE 2. Continued

\begin{tabular}{ll}
\hline Reference & \multicolumn{1}{c}{ Equation } \\
\hline Bairagi et al. (1993) (51) & $E_{c}=(5780-1340 \cdot r) \cdot f_{c}^{0.5}$ \\
KaziKazi et al. (1988) (61) & $E_{c}=1.9 \cdot 10^{5} \cdot\left(\frac{\rho}{2300}\right)^{1.5} \cdot\left(\frac{f_{c}}{2000}\right)^{0.5}$ \\
Ravindrarajah et al. (1987) (62) & $E_{c}=3480 \cdot f_{c}^{0.5}+13050$ \\
Ravindrarajah and Tam (1985) (63) a & $E_{c}=7770 \cdot f_{c}^{0.33}$ \\
Ravindrarajah and Tam (1985) (63) b & $E_{c}=4630 \cdot f_{c}^{0.5}$ \\
Dillman (1998) (64) & $E_{c}=634.43 \cdot f_{c}+3057.6$ \\
\hline
\end{tabular}

Note: $E_{c}=$ Modulus of elasticity $(\mathrm{MPa}) ; f_{c}$ or $f_{c u}$ Compresstive strength $(\mathrm{MPa}) \rho=$ Density $\left(\mathrm{kg} / \mathrm{m}^{3}\right) ; r=$ Replacement ratio $(0 \leq r \leq 1)$; WA $=$ water absorption $(\%)$

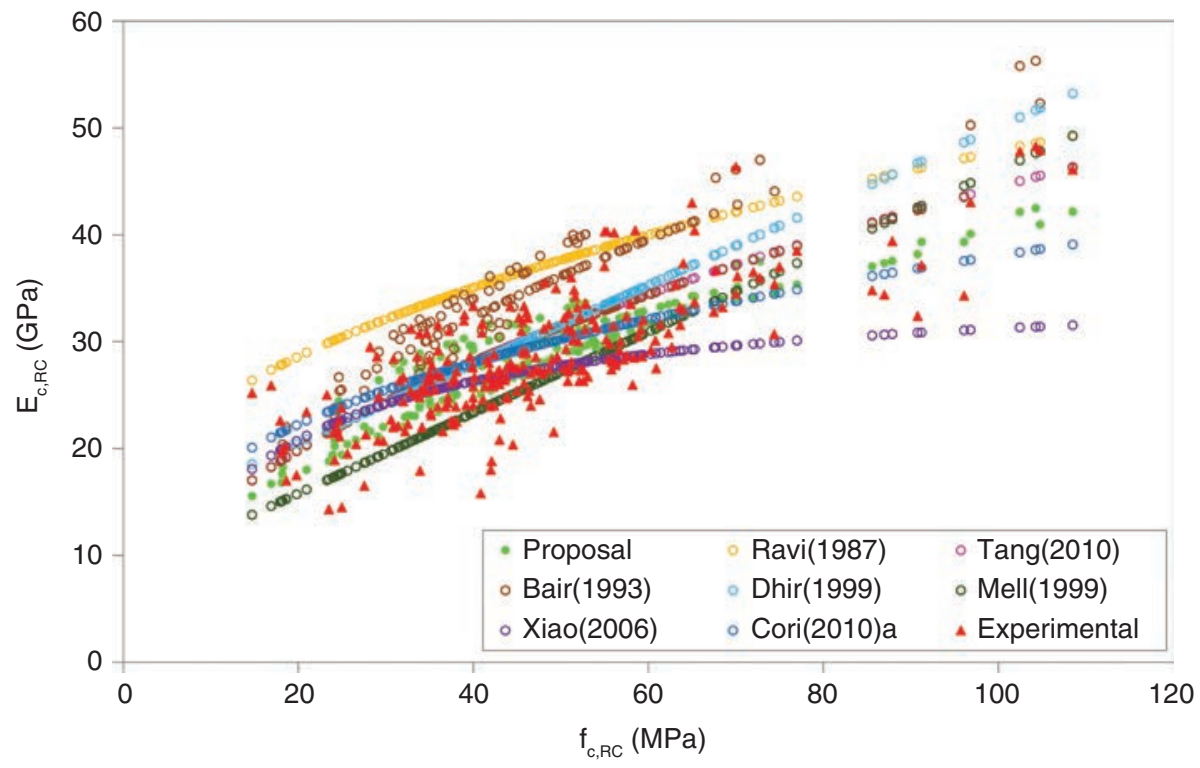

FiguRE 9. Experimental and authors' equations of $E_{R C}(13,36,44,51,57,60,65)$.

1300 experimental data obtained from studies performed between 1980 and 2012 in Japan and Korea and with a statistical analysis proposed a relationship between the compressive strength and modulus of elasticity of recycled aggregate concrete that considers the ratio and types of coarse recycled aggregates.

In this work, using multivariable regression and the database of González-Taboada et al. (9), an expression to predict the structural RC's modulus has been developed (Table 2). It is based on the Eurocode expression, although introducing the replacement ratio and the coarse RCA's quality (considering its water absorption). The equation obtained with multivariable regression shows a Pearson correlation coefficient of 0.78 .

The results obtained with the proposed equation are shown in Figure 9 comparing them with the equations proposed by other authors.

\section{STRESS STRAIN RELATIONSHIP}

The non-linear analysis of structural concrete members can be developed using nonlinear stress-strain relationships for steel and concrete 
in compression. The complete stress-strain curve of plain concrete can be divided in three characteristic parts. The first part represents the linear portion and the second the nonlinear part of the ascending branch. The third part is the descending branch.

The most common parameters with physical significance used to define these curves are the following:

- Maximum stress: usually considered to be the compressive strength of concrete

- Modulus of elasticity: the initial tangent modulus and the secant modulus of elasticity valued between stress 0 and $40 \%$ of the strength of concrete

- Peak strain: strain corresponding to the maximum stress

- Ultimate strain: strain at which failure is defined. Many codes $(66,67)$ consider $3.5 \%$ as the ultimate strain, which corresponds, according to their analytical expressions, to a compressive stress value in the whereabouts of $0.6 \mathrm{fc}$ measured in the descending branch of the curve

Many researchers agree with the fact that RC can present different stress-strain curve from conventional concrete. Folino and Xargay (68) stated that only slight differences were detected among the considered mixes in the strain value corresponding to the peak stress, despite the observed decrease in Young's modulus. However, others (27) found that the peak strain increased with the increase of the coarse RCA content. They observed that the curvature of each ascending branch of the stress-strain curve increased with the increase of the coarse RCA content, while the slope of the descending branch of the complete stress-strain curves decreased as the coarse RCA content increased.

RC has two paste-aggregate interfaces, the interface between adhered mortar and the original aggregate and the new interfacial transition zone between the new mortar and the recycled aggregate. Xiao et al. (20) found that the micromechanical properties of ITZ have an obvious influence on the stress-strain relationship and failure patterns of $\mathrm{RC}$.

\subsection{Stress -strain in compression of RC}

The typical shape of the ascending branch of the stress-strain curve, shown in Figure 10, is very similar to that of conventional concrete regardless of the recycled aggregate replacement ratio (43). The shape is linear up to $0.4 \mathrm{f}_{c}$, and then it becomes parabolic. This leads to the conclusion that the theory of plasticity would be still suitable for structural design process (69).
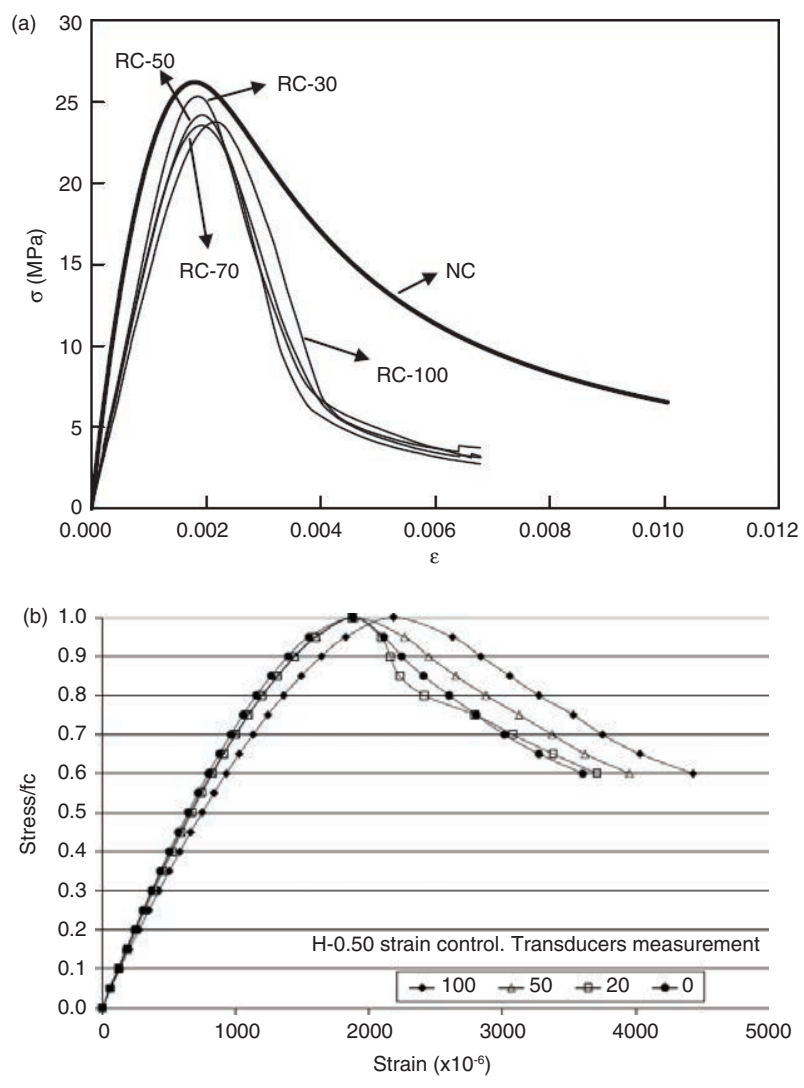

FIGURE 10. Stress - strain curve in compression $(27,43)$.

However, as has been said, there are a large number of interfaces in concrete containing higher proportion of coarse recycled aggregate $(10-12,69)$. Therefore, the strain increases in $\mathrm{RC}$ faster than in conventional concrete. This leads to an increase in the curvature of the stress-strain curves of RC, showing, at the same unit stress, the RC's strains that are higher than those achieved with conventional concrete. This fact is more noticeable as the replacement ratio increases.

Another notable fact that is well-known is that the elasticity modulus of RC is lower than the one of conventional concrete. Again the presence of different interfaces reduce this parameter.

Consequently, both facts result in an increase in the peak strain value, which is particularly significant when high replacement ratios are used. These results had been observed by most authors $(30,33,70)$.

Xiao et al. (27) and Deng et al. (71) studied the peak strain of RAC prisms $(100 \mathrm{~mm} \times 100 \mathrm{~mm} \times$ $300 \mathrm{~mm}$ ) under uniaxial compression with different coarse RCA contents. Du et al. (72) also proved that the peak strain of $\mathrm{RC}$ is much higher than that of conventional concrete. Besides, Rahal (30) found that the strain at the peak compressive stress in RC was 5.5 larger than that in conventional concrete. 
González-Fonteboa et al. (43) analysed the peak strain in cylindrical specimens of $\mathrm{RC}$ with saturated recycled aggregate and also confirmed this result. The same results have been achieved by Zhou et al. (34).

Test results obtained by different authors for peak strains of RC with different coarse RCA contents are shown in Figure 11.

After the peak stress, the major cracks automatically propagate even though the applied load decreases. The post-peak deformation is called work softening. It is characterized by the descending branch of the stress-strain curve, which has a negative tangential stiffness. This descending branch is again similar in $\mathrm{RC}$ and conventional concrete regardless of the recycled aggregate's incorporation ratio. However, the findings regarding its slope are not conclusive.

González-Fonteboa et al. (43) measured the ultimate strain in the descending branch of the curve in a compressive stress value in the whereabouts of $0.6 \mathrm{f}_{\mathrm{c}}$. They observed a decrease in the slope when the recycled aggregate ratio increased (Figure 11). This reduction implies an increase in the ultimate strain (strain at which failure is defined). As in the case of the peak strain, this increase is especially significant when the use of coarse recycled aggregate is high (Figure 11).

Bernier et al. (73) also found that the ultimate strain was higher in RC, obtaining values of about 1.75 for mixes made with coarse recycled aggregate. This fact can be also observed in the curves published by Rühl et al. (74).

Xiao et al. (27) and Deng et al. (71) measured the ultimate strain, in the descending branch of the curve in a compressive stress value in the whereabouts of $0.85 f_{\text {c. It }}$ can be observed (Figure 12) that for a low recycled aggregate content, the ultimate strain decreases, while the opposite may occur for high replacement ratios.

Code proposals for the stress-strain curves are either continuous functions for the ascending and descending branches or two separate functions. For instance, the equation in Eurocode 2 (67) for the ascending and the descending branch up to a strain level of $3.5 \%$ and up to a concrete strength level of $50 \mathrm{MPa}$ is defined as a continuous function.

Different models of stress-strain relationship for $\mathrm{RC}$ in compression have been proposed $(34,43,70)$ (Table 3).

\subsection{Stress -strain in tension of $\mathrm{RC}$}

The uniaxial tensile stress - strain relationship of $\mathrm{RC}$ with different replacement ratios has been studied by Xiao et al. (27) and Liu et al. (75), Figure 13. With an increase in the replacement ratio, the tensile peak strain of RC slightly increased.

\section{SHRINKAGE}

Shrinkage deformation occurs in all concrete types, to a greater or lower extent, depending on various parameters, mainly related with curing conditions and mix proportions. This phenomenon is due to the movement of water inside concrete during its whole service life. However, shrinkage increases nonlinearly over time, growing more significantly at the beginning (up to a year approximately) and tending to stabilize over time.

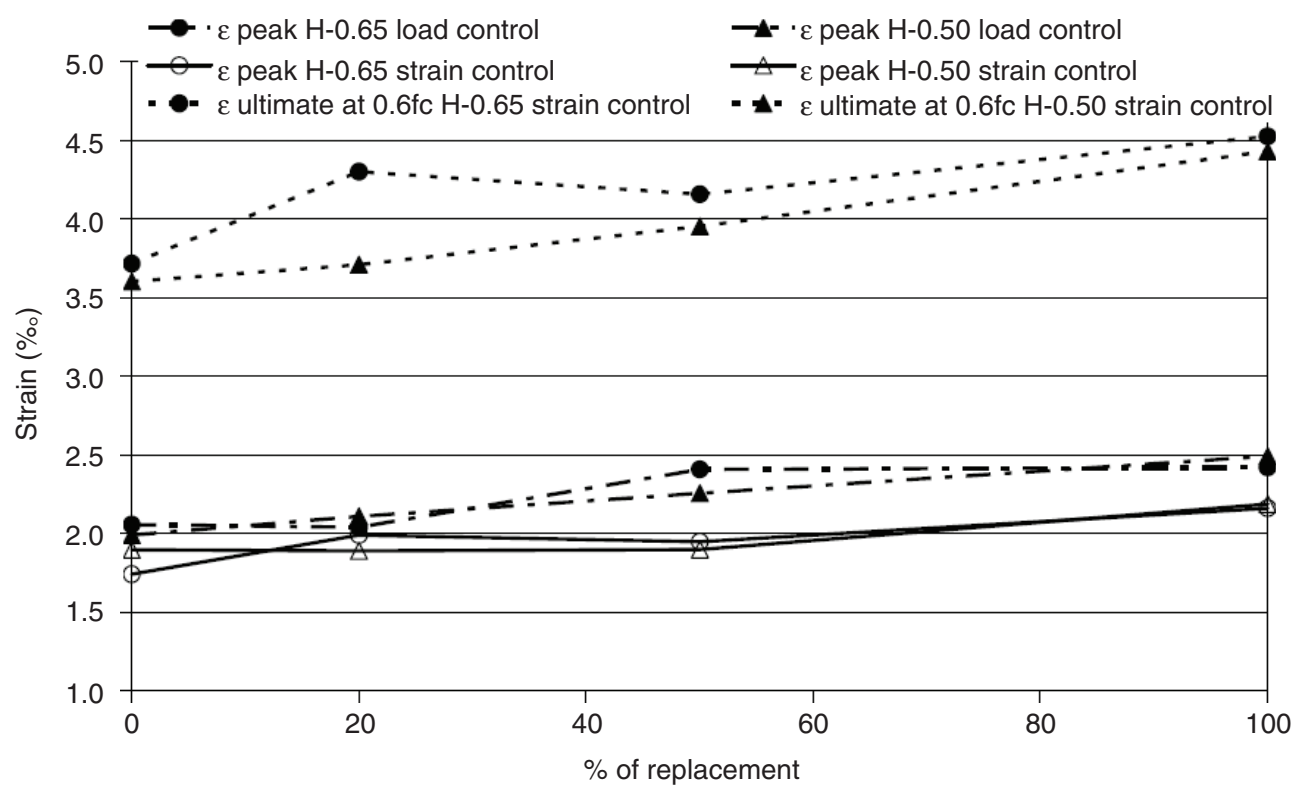

FIgURE 11. Peak strain and ultimate strain (43). 


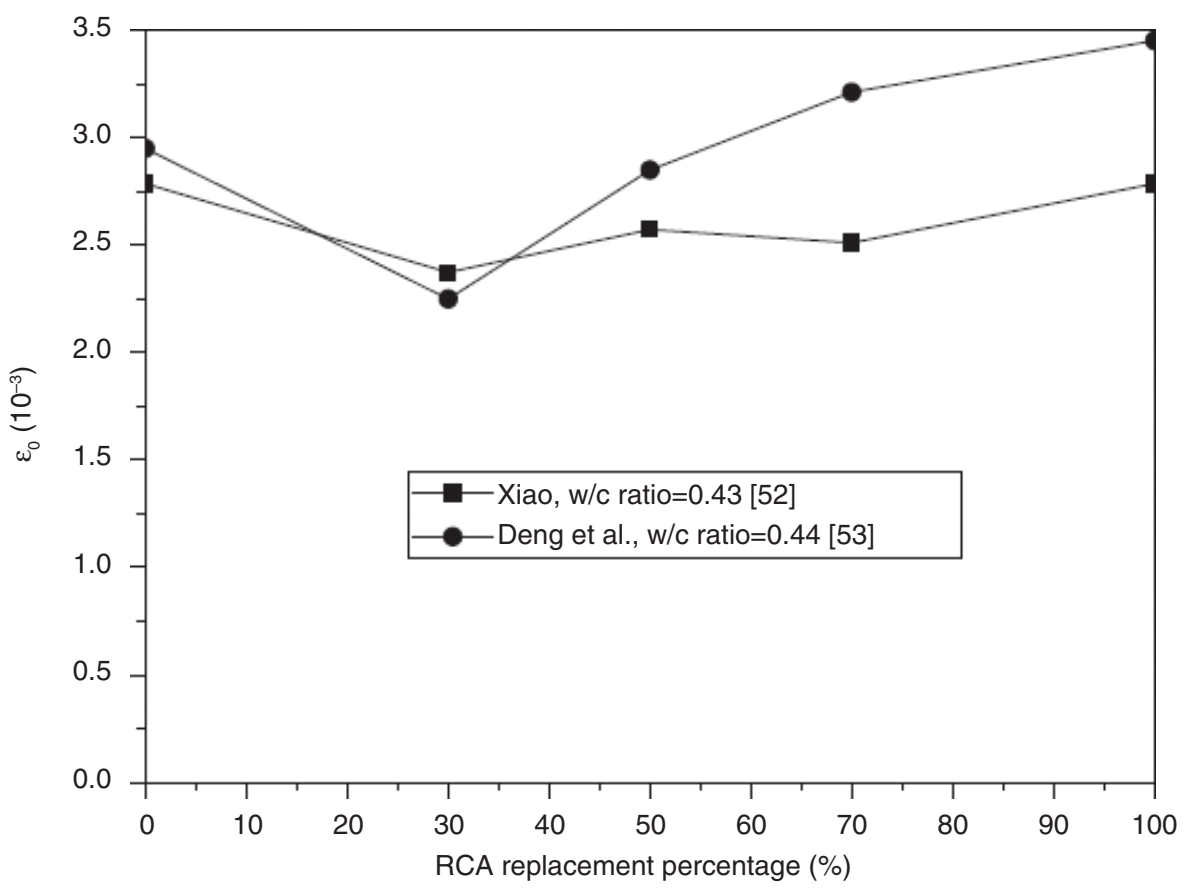

FIGURE 12. Ultimate strain as a function of coarse RCA content (27).

Different authors and codes divide the shrinkage in many types according to diverse parameters. The classification more commonly used consists of distinguishing plastic, autogenous and drying shrinkage (76). The first one occurs at early ages, generally up to 10-12 hours, and occurs under non-saturated conditions, strong winds or high temperatures. Autogenous shrinkage, also named chemical shrinkage, is the result of the cement hydration during concrete hardening without water loss. Lastly, drying shrinkage is attributed to the humidity loss of concrete under non-saturated conditions because of the cement hydration and curing process. This is usually the main component of shrinkage when concrete members are exposed to a non-saturated environment. This kind of shrinkage largely depends on the amount of cement and aggregates' properties. It is widely known that a higher content of cement leads to greater shrinkage. However, the use of aggregates with a significant stiffness contributes to reduce drying shrinkage. Accordingly, it is expected that the use of recycled aggregate leads to greater shrinkage deformations due to its higher water absorption (which results in higher water demand) and lower stiffness than natural aggregates.

Although most authors conclude that shrinkage increases up to $35-80 \%$ in concrete with $100 \%$ recycled aggregate $(2,49,62,77,78)$, a few have stated that this concrete may show similar shrinkage deformations to that obtained in conventional concrete, even with replacement ratios of $100 \%$, when using high-quality recycled aggregate or different mixing methods $(10,69,79,80)$. Kou et al. (10) analysed the effect of using recycled aggregates with different water absorption coefficients and composition. Their results revealed that concrete made with $100 \%$ of low-grade recycled aggregate showed an increment of shrinkage of $59 \%$, while these differences decreased to $35 \%$ with high-quality recycled aggregate. As aforementioned, the water absorption of recycled aggregate and its composition (amount of old mortar, clay bricks or other impurities) are some of the main features that define the quality of recycled aggregate and, consequently, its higher or lower impact on concrete properties $(14,81)$.

The quality of the aggregates is directly related to the shrinkage deformation of concrete. The adhered mortar of the recycled aggregate produces a weaker ITZ resulting in less aggregate-restrained shrinkage $(6,69)$, and consequently higher concrete deformations. This effect also influences other concrete properties such as creep or strength. Therefore, the shrinkage of RC not only depends on the incorporation ratio of coarse aggregate but also on the aggregate's properties.

Regarding RC with low replacement ratios (20-30\%), different researches revealed that its shrinkage presents values slightly higher than those obtained in conventional concrete (increments of $3-8 \%)(2,10,78)$. When replacement get up to $50 \%$, the shrinkage deformations in $\mathrm{RC}$ are $13-33 \%$ higher than those registered in conventional concretes. In general, shrinkage grows as the replacement ratio increases $(2,6,69,78,80,82,83)$. 
TABLE 3. Models of stress-strain relationship for RC

González-Fonteboa et al. (43)

Xiao et al. (70)

$$
\sigma_{c} / f_{c m}=\left[k \cdot \eta-\eta^{2}\right] /[1+(k-2) \cdot \eta]
$$

where:

$\sigma_{\mathrm{c}}=$ compression stress

$\eta=\boldsymbol{E}_{c} / \boldsymbol{\varepsilon}_{c 1}$ where $\varepsilon_{c 1}$ is the strain at peak stress and $\varepsilon_{c}$ is the strain in compression

$\varepsilon_{c l}=0.7(0.21 \cdot r+1)\left(f_{c m}\right)^{0.31}$

$k=1.05 E_{c m} \cdot\left|\varepsilon_{c 1}\right| / f_{c m}$

$f_{c m}=$ mean compressive stress at 28 days

$f_{c m}=f_{c k}+8$, and $\mathrm{f}_{\mathrm{ck}}$ is the characteristic $(5 \%)$ cylinder strength

$E_{c m}=$ secant longitudinal modulus of elasticity

$E_{c m}=22(-0.20 \cdot \mathrm{r}+1)\left(\mathrm{f}_{\mathrm{cm}} / 10\right)^{0.30}$

$\varepsilon_{c} \leq £ \varepsilon_{c u}=0.0035 \cdot(0.22 \cdot r+1)$

$r=$ ratio of recycled aggregate $(0 \leq r \leq 1)$

Zhou et al. (34)

$$
y=\left\{\begin{array}{l}
a x+(3-2 a) x^{2}+(a-2), 0 \leq x<1 \\
\frac{x}{b(x-1)^{2}}+x, x \geq 1
\end{array}\right.
$$

where:

$x=\varepsilon_{c} / \varepsilon_{c l}$ (being $\varepsilon_{c l}$ the strain at peak stress)

$y=\sigma_{c} / f_{c}$

$a$ and $b$ are fitting constants, represented as the initial elastic modulus and related to the shape of the descending branch of the stress-strain curve, respectively

$a=2.2 \cdot x \cdot\left(0.748 r^{2}-1.231 r+0.975\right)$

$b=0.8 \cdot x \cdot(7.6483 r+1.14)$

$\mathrm{r}$ is the incorporation of recycled aggregate.

Xiao (27)

$$
y=\left\{\begin{array}{l}
a x+(3-2 a) x^{2}+(a-2), 0 \leq x<1 \\
\frac{x}{b(x-1)^{2}}+x, x \geq 1
\end{array}\right.
$$

where:

$x=\varepsilon_{c} / \varepsilon_{c l}$ (being $\varepsilon_{c l}$ the strain at peak stress)

$y=\sigma_{c} l f_{c}$

$a$ and $b$ depend on the type of recycled aggregate used.

If the concrete with recycled aggregate obtained from crushed waste concrete with crushed rock is analysed, these parameters are:

$\mathrm{a}=1.15$

$\mathrm{b}=12.43$

Otherwise, if concrete is made with recycled aggregate obtained from crushed waste concrete with natural pebbles, these values are:

$\mathrm{a}=1.17$

$\mathrm{b}=4.58$

$y=g x-(g-1) x^{6}$

$x=\varepsilon_{c} / \varepsilon_{c l}$ (being $\varepsilon_{c l}$ the strain at peak stress)

$y=\sigma_{c} l f_{c}$

$\mathrm{g}$ is related to the coarse RCA incorporation ( $\mathrm{r}$ ) and can be determined by:

$\mathrm{g}=0.07 \mathrm{r}+1.19$ 
Collecting the data of different authors $(2,6$, $10,56,69,77,78,80,82,83)$ Figure 14 analyses the relationship "RC's shrinkage-reference concrete's shrinkage" taking into account different ratios of coarse recycled aggregate, from $20 \%$ to $100 \%$. This figure confirms that the recycled aggregate ratio influences the shrinkage gain.

According to Eckert and Oliveira (84), the use of a specific mixing process mitigates the negative effects of high water absorption of recycled aggregates especially at early ages, resulting in lesser shrinkage deformation and consequently, lower early age cracking. This effect is attributed to the internal curing caused by the use of pre-saturated aggregates or extra water compensation method

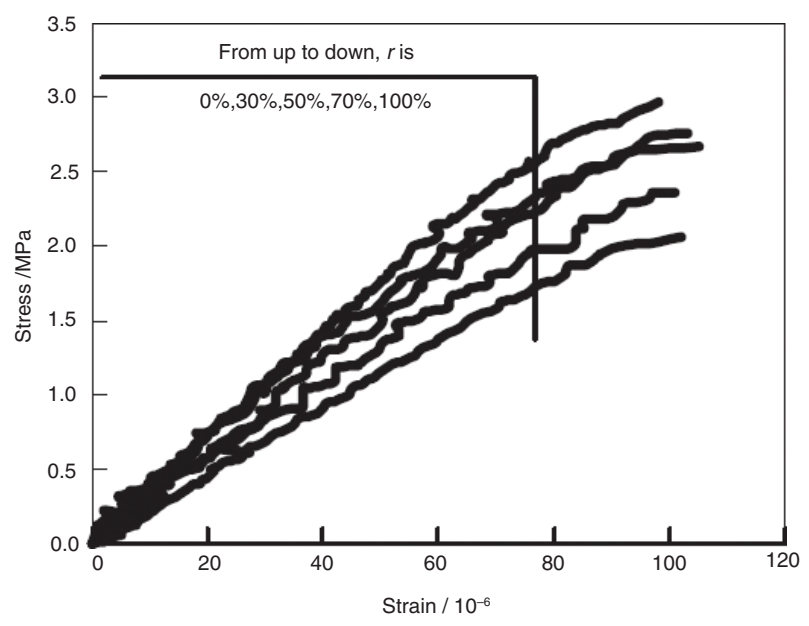

Figure 13. Stress - strain curve in tension (27).
$(2,6,21,36,69)$. However, this curing effect is not enough to counteract the lower stiffness of recycled aggregates, which leads to poorer performance of concrete in terms of strength and deformability.

Shrinkage deformation occurs mainly during the first year, tending to stabilize over time. In this regard, both conventional and $\mathrm{RC}$ usually show the same pattern. However, some authors have found that the use of recycled aggregates, especially under saturated conditions, leads to a different concrete shrinkage evolution over time resulting in lower deformations at early ages that grow to a greater extent after this period of internal curing $(2,6,21$, $36,83)$. Therefore, RC show generally a different development, especially at early ages, compared to that of the conventional concrete.

Regardless of the replacement ratio, other concrete parameters and external factors are essential to determine shrinkage deformation. One of these is the w/c ratio, which has a noticeable effect on shrinkage. Higher w/c ratios lead, in general, to greater deformations due to the presence of a higher amount of water, both in conventional and RC mixes. However, Seara et al. (81) found that concrete with low w/c ratio shows greater influence of using recycled aggregates because the new concrete is governed by the effect of bonding between the old and the new ITZ of concrete. It is expected that the lower the w/c ratio is the better the quality of the cement paste. Therefore, reference concrete with a low w/c ratio increases the strength and stiffness of its ITZ, while RC weakens it due to the presence of adhered mortar in recycled aggregates. As a result, the content of recycled aggregates influences concrete deformability in a greater extent when using

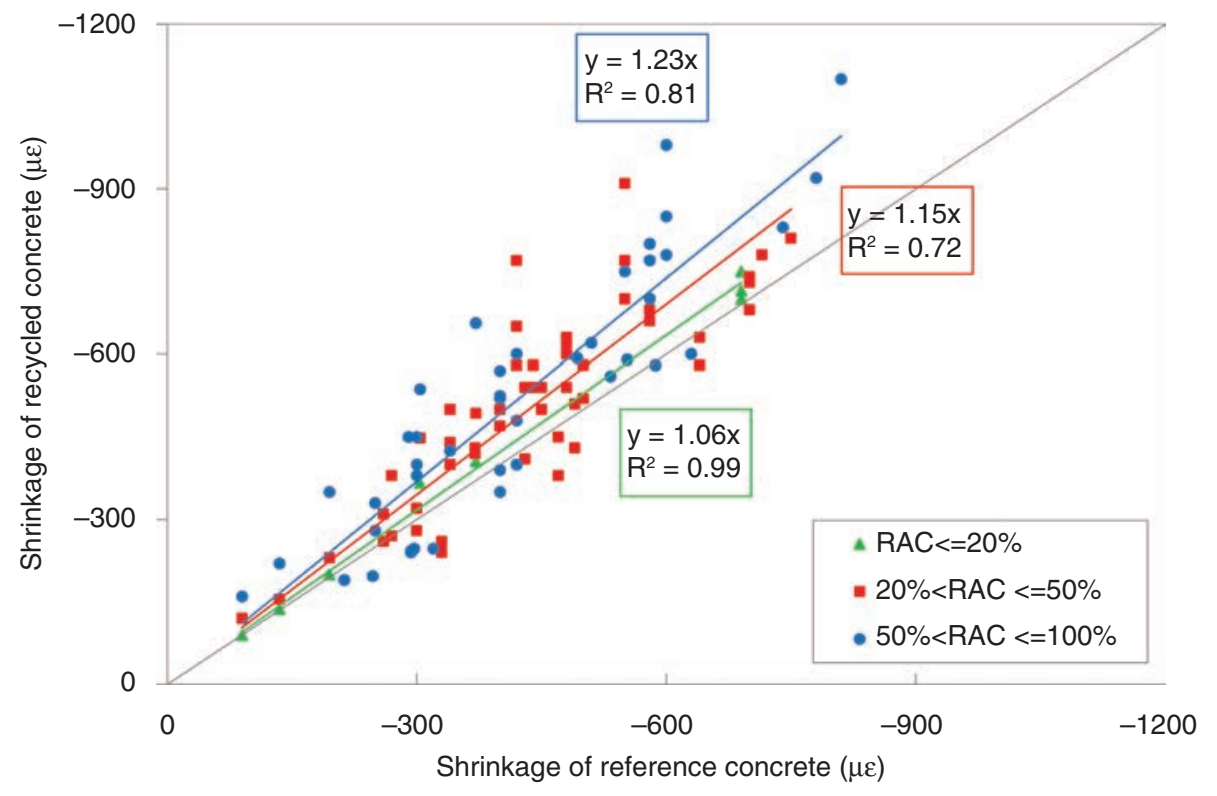

FIGURE 14. Shrinkage of reference concrete vs. shrinkage of RC. 
low w/c ratios. This effect also influences other concrete properties such as compressive strength or splitting tensile strength (11).

Another factor that influences concrete shrinkage is the hygrometric conditions of the external environment. Humidity and temperature are key factors on shrinkage development leading to higher drying shrinkage when humidity lessens, or greater shrinkage at high temperatures (85). Additionally, the curing process may reduce the concrete strain due to shrinkage $(86,87)$. In a recent research, Hanif et al. (88) reported that the use of recycled aggregates with high early strength cement and steam curing method led to an improvement of shrinkage performance, lowering early-age cracking.

Regarding code predictions, some authors (2, 69,83 ) proposed modified expressions to calculate shrinkage deformation involving the content of recycled aggregate used. Fathifalz et al. (69) noted that existing models usually applied to conventional concrete include the volume of aggregates, cement and properties of cement paste. Therefore, these models need to be modified in order to consider the influence of different ITZs, old mortar-new mortar and aggregate-old mortar. Seara et al. (2) found that, in general, code expressions predict higher shrinkage strains than those experimentally obtained and proposed a modified expression to predict RC's shrinkage involving both the replacement ratio and the specific behaviour of $\mathrm{RC}$ at early ages with the same approximation degree in $\mathrm{RC}$ and conventional concrete.

In this work, using multivariable regression and data of different authors $(2,6,10,56,69,77,78,80)$, an equation to calculate the shrinkage of $\mathrm{RC}$ was developed [Eq. 4] (Figure 15). This equation has a Pearson correlation coefficient of 0.863 .

$S h_{R C}=S h_{C, C O D E} \cdot(1-0.026 \cdot r) \cdot e^{\left[(0.393 \cdot r \cdot) \cdot\left(1-\left(\frac{90}{t}\right)^{(1.299-1.145 \cdot r)}\right)\right]}$

\section{CREEP}

Since a load is applied to a concrete structure, the long-term deformations are determined by not only its shrinkage performance but also its creep coefficient. It is well known that creep performance depends on different concrete parameters such as concrete strength and cement (49). In this regard, it is expected that the higher deformability of RC leads to greater creep strains than conventional ones. Xiao et al. (85) found that the creep mechanism is strongly affected by the use of coarse recycled aggregates, mainly due to the old mortar adhered to the original aggregates, which generates a weaker ITZ and higher concrete deformability. This leads to a change in stress distribution of mortar and aggregates over time during the creep process, both at early and latter ages. Similar findings have been reported by other authors $(2,6$, $69,78,89,90$ ), who noted largely higher (up to $84 \%$ ) creep strains in concrete fully made with coarse recycled aggregates than in conventional concrete, while these increments lessened to $5-26 \%$ in concrete with low replacement ratios $(20-30 \%)$ (Figure 16).

The mixing of new and old cement mortar affects the creep behaviour of RC. Hence, since the

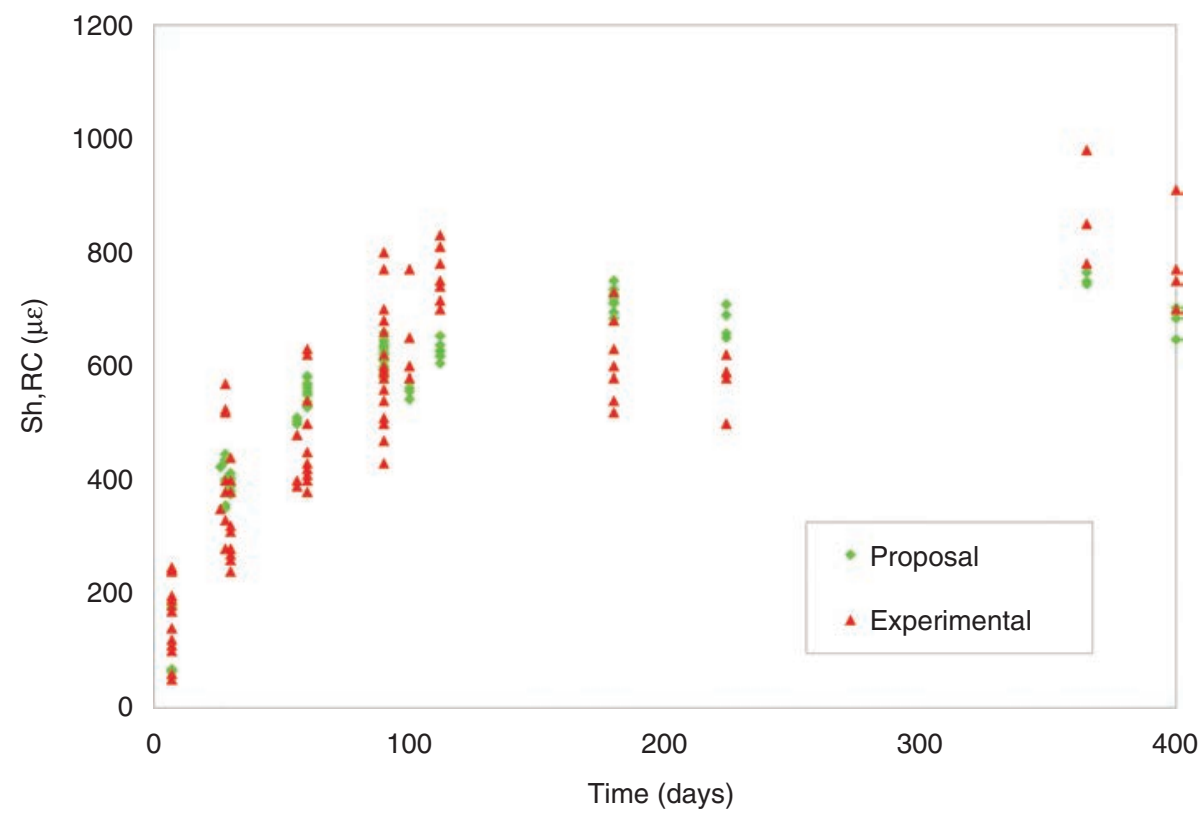

FIGURE 15. Shrinkage experimental and proposal. 

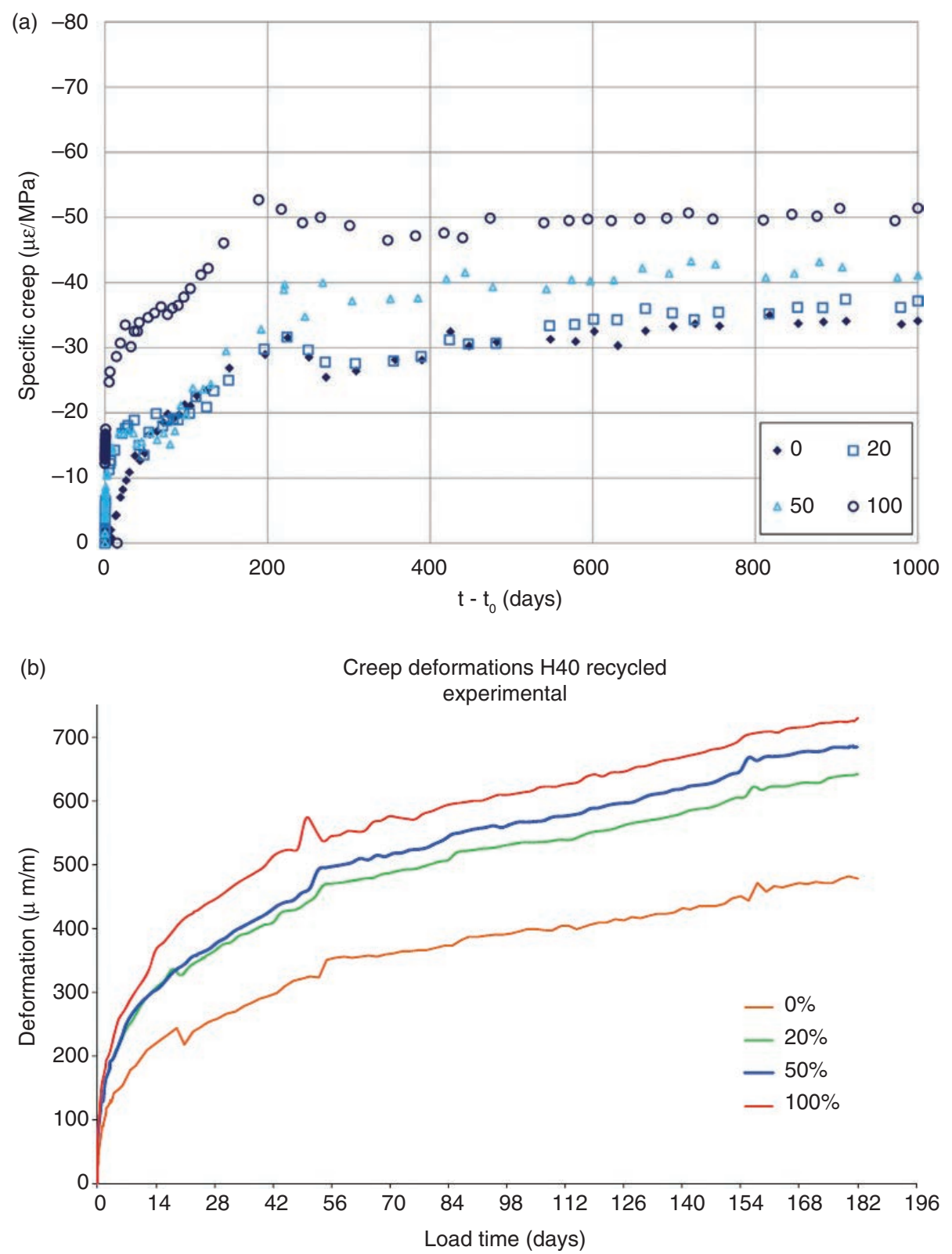

Figure 16. Creep of RC $(2,78)$.

mortar content is the main factor influencing creep deformation, a higher content of recycled aggregates increases the creep strain $(2,6,69,80,91,92)$. However, the experimental results obtained from other researches show a different trend for RC's creep, i.e. a decrease of $17-20 \%$ relative to that of conventional concrete $(6,49)$. Nishibayashi and Yamura (93) studied the specific creep of RC and found as well lower creep deformation than in conventional concretes.

Regarding the environmental conditions, unlike for shrinkage, it is not clear that humidity and temperature significantly influence creep deformation (85). Furthermore, it is well known that the w/c ratio influences the mechanical properties and deformational behaviour of concrete. As expected, concrete with higher w/c ratios have greater creep deformations, both in RC and conventional concrete, because the use of a higher amount of water reduces the mechanical strength and increases concrete deformability (82). However, Masato et al. (94) point out that the creep of $\mathrm{RC}$ is higher than that of conventional ones regardless of the w/c ratio and attributes this to the old mortar adhered in recycled aggregates. Another important factor that influences creep performance is the effect of reinforcing steel, which reduces the concrete deformation due to the restraint of reinforcing steel. 
Table 4 summarizes the main results obtained by different authors in terms of creep increments compared to conventional concrete.

In terms of creep development over time, some authors $(2,21,36)$ pointed out that, at early ages, internal curing influences the RC's properties and, consequently, creep performance. Again, this effect is attributed to bleeding of water inside aggregate pores to cement paste. Additionally, the ITZ of $\mathrm{RC}$ is weaker than that of conventional aggregates because of the attached mortar. As a result, these effects cause a delay in cement hydration and consequently, lower RC's strengths and higher early-age deformability $(6,36)$, not only due to the weaker ITZ but also to the internal curing effect.

The creep coefficient is an essential parameter to accurately design concrete structures. The use of coarse recycled aggregates influences creep coefficients to a lesser extent than other deformationrelated properties. $\mathrm{RC}$ made with replacement ratios up to $50 \%$ provided creep coefficients similar to those obtained in conventional concrete (2). Concrete fully made with recycled aggregates presents creep coefficient higher than those of conventional ones, about $11-45 \%$ depending on concrete parameters. These increments are attributed to the lower modulus of elasticity of the RC that results in higher deformability. This effect is more noticeable as the replacement ratio increases.

Regarding creep predictions, most authors stated that code expressions provide quite suitable creep coefficients of RC. However, Seara et al. (2) found that the internal curing effect influences the development of the creep coefficients of RC up to 90 days. Consequently, a modified expression was proposed to take into account this effect at early ages.

\section{DURABILITY}

In spite of the continuous strength development of concrete, there are a number of factors, both internal and external, that induce the material's

TABLE 4. Increments of creep in RC

\begin{tabular}{|c|c|c|c|c|}
\hline Author & w/c & Absorption (\%) & Recycled aggregate (\%) & Increment of creep (\%) \\
\hline \multirow[t]{6}{*}{ Seara et al. (2016) (2) } & 0.5 & 5.4 & 20 & 18 \\
\hline & 0.5 & & 50 & 19 \\
\hline & 0.5 & & 100 & 84 \\
\hline & 0.65 & & 20 & 9 \\
\hline & 0.65 & & 50 & 20 \\
\hline & 0.65 & & 100 & 51 \\
\hline \multirow[t]{2}{*}{ Manzi et al. (2013) (6) } & 0.48 & 7 & 27 & -17 (specific) \\
\hline & & 9 & 63.5 & 17 (specific) \\
\hline Fathifazl et al. (2011) (69) & 0.45 & 5.4 & 100 & 32 \\
\hline \multirow[t]{3}{*}{ Domingo et al. (2009) (78) } & 0.5 & 5.19 & 20 & 35 \\
\hline & & & 50 & 42 \\
\hline & & & 100 & 51 \\
\hline Yang et al. (2008) (95) & 0.55 & -- & 50 & 23 \\
\hline \multirow[t]{4}{*}{ Masato et al. (2006) (94) } & 0.40 & 4.8 & 100 & 44 (specific) \\
\hline & 0.60 & 5.4 & & 31 (specific) \\
\hline & 0.40 & & & 56 (specific) \\
\hline & 0.60 & & & 25 (specific) \\
\hline Ajdukiewicz et al. (2002) (49) & 0.41 & -- & 100 & -20 \\
\hline \multirow[t]{4}{*}{ Gómez Soberon. (2002) (90) } & -- & -- & 15 & 5 \\
\hline & & & 30 & 16 \\
\hline & & & 60 & 32 \\
\hline & & & 100 & 45 \\
\hline \multirow[t]{3}{*}{ Limbachiya et al. (2000) (96) } & -- & -- & 30 & 2 \\
\hline & & & 50 & 22 \\
\hline & & & 100 & 65 \\
\hline \multirow[t]{2}{*}{ Nishibayashi and Yamura (1988) (93) } & -- & -- & 100 & $30\left(\mathrm{c}=250 \mathrm{~kg} / \mathrm{m}^{3}\right)$ \\
\hline & & & & $50\left(\mathrm{c}=350-450 \mathrm{~kg} / \mathrm{m}^{3}\right)$ \\
\hline
\end{tabular}


deterioration. The concept of concrete durability, though difficult to quantify, can be assessed by looking into the material's main influencing properties. In the case of structural concrete, the most common degradation phenomenon is related to the steel reinforcements' corrosion, which is potentiated by a low resistance to chloride ion penetration and a high progression rate of carbonation. Another characterizing property of the durability of concrete is its ability to withstand several freezing and thawing cycles, without presenting a severe decline in its original performance. Further durability-defining properties include the concrete's resistance to disintegration of the cementitious matrix, when subjected to chemically aggressive environments, and its resistance to abrasion due to repetitive mechanical actions.

\subsection{Porosity and permeability}

The deterioration of a cementitious matrix is dependent on its porosity, which is related to the amount of surface area that is prone to be "attacked" by deleterious chemical reactions. Assessing the water absorption of concrete has been one of the most common and expedite approaches to indirectly evaluate the porosity of RAC and thus its potential durability. Studies on the matter show a consensus in that, for a given mix design, concrete containing increasing quantities of RCA will exhibit a higher water absorption capacity than that of corresponding NAC specimens $(21,59,97-104)$. This phenomenon is natural considering the notable water absorption increase of the RCA themselves as a result of the porous adhered mortar, which is the main factor influencing the overall permeability of the new concrete containing them.

When the coarse natural fraction is fully replaced by $\mathrm{RCA}$, a $30 \%$ to $70 \%$ increase in water absorption relative to that of the corresponding NAC is expected. The magnitude of this increase is mostly affected by the content of adhered mortar existing in the RCA and, to some extent, by the strength of the source concrete. Nagataki et al. (16) studied the effect of using RCA coming from products with varying target strengths and that were subjected to a varying number of processing stages. RCA subjected to more crushing stages exhibited lower adhered mortar contents (between $30.2 \%$ and $32.3 \%$ ), whereas RCA that underwent a more basic crushing process present higher contents (between $52.3 \%$ and $55.0 \%$ ). The former yielded RAC specimens with lower levels of porosity when compared to the use of the latter RCA. Furthermore, specimens made with the first RCA, which were sourced from products with w/c ratios ranging from 0.63 to 0.35 , presented clear decreasing porosity levels as the strength of the source concrete increased. This can be explained by the denser cementitious microstructure of higher strength concrete, which is likely to result in RCA with lower porosity.

Similar findings were recently reported in the study of Pedro et al. (103) in which RCA were obtained from concrete products with different target strengths and subjected to different number of crushing stages (i.e. varying adhered mortar content and shape). Lower water absorption values were observed in specimens containing RCA from higher strength concrete and subjected to more crushing stages.

Padmini et al. (105) had also previously studied the influence of introducing RCA from concrete products with different strength classes. However, the authors observed that RCA from products with higher strength led to the production of RAC with higher water absorption values. Although this may seem counterintuitive, it can be explained by the fact that these RCA exhibited higher adhered mortar content when compared to RCA coming from low strength concrete products.

Apart from the adhered mortar content and target strength of the source concrete product, the shape, moisture content, and contamination level of RCA may also influence the permeability of concrete. Matias et al. $(106,107)$ evaluated the effect of using RCA with different shape indexes on the concrete's permeability. The results showed that the use of elongated RCA led to an increase of around 19\% when compared to the control concrete, whereas specimens with rounder RCA exhibited an increase of $12 \%$.

Regardless of the substitution level, the moisture state at which the RCA are incorporated into the mix also has a considerable influence on the overall porosity of RAC. Ferreira et al. (102) observed that, applying a water compensation approach, wherein an extra quantity of water is added to the mix, would yield RAC with slightly lower water absorption by immersion and by capillary action in comparison with RAC containing pre-saturated RCA. This can be explained by the bleeding of water of the latter RCA and/or, as a result of inadequate drying processes, these pre-saturated RCA may present water in the surface's pores, which induces slightly higher local effective w/c ratio thereby causing higher porosity. Tam et al. (108)obtained similar results with the use of a slightly different mixing procedure, in which the coarse RCA absorbed part of the mixing water in the initial stage of the process. This prompted a higher initial absorption of the mixing water, which decreased the effective w/c ratio of the mix thereby resulting in a matrix exhibiting lower permeability.

Poon and Chan (109) analysed the effect of introducing RCA with $10 \%$, by weight, of different types of contaminants (i.e. brick, glass, tile, and wood particles) on the properties of concrete. The presence of these contaminants led to increases in water 
absorption levels of $35 \%$ to $60 \%$, when compared to that of specimens with uncontaminated RCA. This increase was even higher when wood particles were incorporated, leading to an $80 \%$ increase in water absorption.

Another factor that influences the porosity of RAC is the time taken for the formation of further products of hydration. Kou et al. (110) assessed the pore size distribution of NAC and RAC after 28 days, 1 year and 5 years. After 28 days, the cumulative distribution of pores indicated a greater porosity by RAC made with $100 \%$ coarse RCA in comparison with the corresponding control concrete. However, after 5 years of being exposed to water curing, RAC specimens exhibited lower porosity levels (porosity reduced by $45 \%$ between the ages of 28 days and 5 years).

\subsection{Carbonation}

The literature indicates that increasing the coarse RCA content is likely to lead to greater carbonation of the cementitious microstructure, when compared to control mixes with equivalent mix design, as a result of the higher porosity of the adhered mor$\operatorname{tar}(64,77,101,111-114)$. Having a microstructure exhibiting greater porosity facilitates the propagation of atmospheric $\mathrm{CO}_{2}$, which, in the presence of some humidity, will react with the material's calcium hydroxide $\left(\mathrm{Ca}(\mathrm{OH})_{2}\right)$ resulting in calcium carbonate $\left(\mathrm{CaCO}_{3}\right)$. This process induces an overall reduction of the concrete's $\mathrm{pH}$, which results in the depassivation of the steel reinforcement.

The incorporation of $100 \%$ coarse RCA is expected to result in increases in carbonation depth by $20 \%$ to $80 \%$ in comparison with the corresponding NAC. The variation between these two values depends on several factors related to the mortar adhered to the surface of RCA (i.e. its content, w/c ratio of the source concrete, moisture content) (24). The quantity of adhered mortar has a significant influence on the carbonation resistance of concrete. Figure 17 presents the results of Pedro et al. (21) in which an extensive experimental investigation was carried out on the effects of incorporating $100 \%$ coarse RCA, from products exhibiting varying strength classes and exposed to different numbers of crushing stages, on the properties of concrete. The RCA that were subjected to a primary plus secondary crushing stage ultimately became rounder and with lower adhered mortar content. Their use yielded specimens exhibiting consistently lower carbonation depths in comparison with those made with RCA subjected to a single crushing stage (i.e. higher adhered mortar content). In spite of the influence of this constituent, the prime variable affecting the resistance to carbonation is the w/c ratio of the new cement paste. Indeed, Figure 17 shows that the relative increase in the coefficient

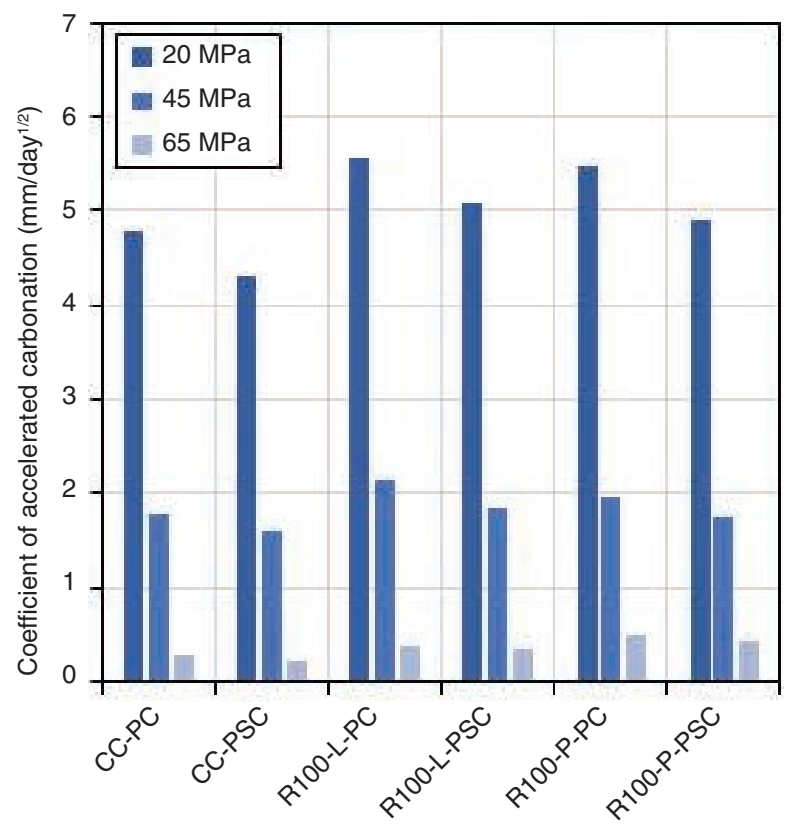

FIGURE 17. Coefficients of accelerated carbonation of concrete containing RCA from products made in a laboratory environment (L) or from the precast concrete company $(\mathrm{P})$, which were subjected to a single primary crushing (PC) or primary + secondary crushing stages (PSC) (data sourced from Pedro et al.) (21).

of accelerated carbonation prompted by the incorporation of $100 \%$ coarse RCA became insignificant with the increasing strength class of concrete; the coefficients of accelerated carbonation of concrete specimens with a target strength of $65 \mathrm{MPa}$ were only a fraction (between $5.3 \%$ and $8.7 \%$ ) of those of the corresponding specimens with $20 \mathrm{MPa}$.

In the Ryu (115) study, concrete mixes were produced with a w/c ratio of 0.55 and made with coarse RCA from materials with variable strength and adhered mortar content. All RAC mixes with $100 \%$ coarse RCA exhibited $20 \%$ greater carbonation depths, which led the author to conclude that the strength of the source concrete and the amount of adhered mortar had little or no effect on the carbonation depth of RAC relative to that of the corresponding NAC. However, in spite of the varying adhered mortar content, all RCA had equivalent levels of water absorption and thus similar porosity between them thereby explaining the marginal effect on the carbonation depths. Similar findings have been reported by other researchers $(112,114$, 116, 117).

Some researchers $(99,101)$ carried out investigations to ascertain whether exposing RAC to different environmental conditions has any effect on the carbonation depth relative to that of corresponding NAC. As expected, when specimens were cured in progressively drier environments, the carbonation depths increased for all mixes. When compared to 
the corresponding control specimens, the carbonation rate of RAC for a given replacement ratio was similar, regardless of the curing conditions. This means that the curing conditions have marginal effect on the carbonation of RAC with increasing substitution levels, compared with NAC.

Among the literature's findings, the results of only one study indicated equivalent resistance to carbonation between RAC and NAC (118). In that investigation, the authors produced mixes with equivalent total $\mathrm{w} / \mathrm{c}$ ratio and incorporated RCA at an air-dry state, which led to the absorption of part of the mixing water thereby reducing the effective w/c ratio (also demonstrated by the enhanced mechanical performance with increasing replacement levels). However, since the coarse RCA also presented some porosity, there may have been a combination of opposing effects, which, by cancelling each other, resulted in specimens with equivalent carbonation depth to corresponding NAC mixes.

Kou and Poon (119) studied the long-term durability properties of RAC prepared with increasing coarse RCA and varying fly ash content. The carbonation depths of concrete mixes, which had been exposed to an outdoor environment, were measured after 28 days, 1, 3, 5 and 10 years. All concrete mixes were produced with a w/c ratio of 0.55 and a cement content of $410 \mathrm{~kg} / \mathrm{m}^{3}$, which was replaced with $25 \%$, $35 \%$ and $55 \%$ by weight of fly ash. As expected, this caused an overall increase of the carbonation rate, due to the decreased quantity of $\mathrm{Ca}(\mathrm{OH})_{2}$. It was observed that the carbonation development of RAC mixes was parallel to that of the corresponding NAC mixes over time. After 1 year, carbonation was progressing at a linear rate of 0.80 to $0.85 \mathrm{~mm} /$ year, irrespective of the replacement level. After 10 years of being exposed to an outdoor environment, the carbonation depths of the control concrete increased between $11 \%$ and $25 \%$ with the use of $100 \%$ coarse RCA and between $67 \%$ and $89 \%$ when $55 \%$ fly ash was used as cement replacement thus showing a considerably greater influence on this property (Table 5).

\subsection{Chloride ion penetration}

The depassivation of steel reinforcements is also potentiated by the penetration of chloride ions. These surround the reinforcement bars, reacting as anodic points, forming hydrochloric acid, destroying the passive layer, with subsequent corrosion in the form of localized pitting (Neville and Brooks, 2010). The diffusion mechanism of chloride ions occurs in a way comparable to that of carbonation and is mostly dependent on the porosity of the cementitious matrix. For this reason, the literature's findings have revealed that the increasing incorporation of coarse RCA tends to lead to higher chloride ion penetration depths $(21,99,104,120-125)$.
TABLE 5. Carbonation depth of concrete mixes with increasing coarse RCA and fly ash content (data sourced from Kou and Poon (119))

\begin{tabular}{lccc}
\hline Mix & $\begin{array}{c}\text { Carbonation } \\
\text { depth after } \\
\text { 10 years (mm) }\end{array}$ & \begin{tabular}{c} 
Relative value with increasing: \\
\cline { 3 - 4 } Replacement \\
level
\end{tabular} & $\begin{array}{c}\text { Fly ash } \\
\text { content }\end{array}$ \\
\hline R0 & 12.09 & - & - \\
R50 & 12.79 & 1.06 & - \\
R100 & 13.36 & 1.11 & - \\
R0F25 & 13.61 & - & 1.13 \\
R50F25 & 14.43 & 1.06 & 1.13 \\
R100F25 & 15.54 & 1.14 & 1.16 \\
R0F35 & 15.68 & - & 1.30 \\
R50F35 & 17.22 & 1.10 & 1.35 \\
R100F35 & 18.37 & 1.17 & 1.38 \\
R0F55 & 20.25 & - & 1.67 \\
F50F55 & 22.64 & 1.12 & 1.77 \\
R100F55 & 25.25 & 1.25 & 1.89 \\
\hline
\end{tabular}

Considering the beneficial outcomes of using pozzolanic additions (i.e. fly ash, silica fume, ground granulated blast furnace slag and metakaolin) on the resistance to chloride ion penetration, there have been several studies assessing the interaction between their use, as partial cement replacement, and increasing recycled aggregate content. Kou et al. (126) evaluated the effect of using several types of mineral additions as partial cement replacement. Although the use of increasing coarse RCA content led to higher total charge passed when compared to corresponding control specimens, this difference became negligible after replacing part of the cement with different types of additions; decreases of $21 \%$, $24 \%, 28 \%$ and $31 \%$ were observed after replacing $10 \%, 15 \%, 35 \%$ and $55 \%$ of the cement with silica fume, metakaolin, fly ash and ground granulated blast furnace slag, respectively. Moon et al. (127) reported that replacing $10 \%$ of the cement with metakaolin or silica fume led to decreases of about $55 \%$ in the total charge passed when compared to corresponding mixes with $100 \%$ coarse RCA and without additions. In other studies $(128,129)$, it was reported that the use of ground granulated blast furnace slag, used as partial cement replacement, at ratios between $30 \%$ and $65 \%$, led to decreases in the total charge passed of about $50 \%$.

Kou and Poon (119) studied the influence of incorporating increasing coarse RCA and fly ash content on the long term mechanical and durabilityrelated performance of RAC over the course of 10 years. Figure 18 presents the total charge passed of concrete specimens produced with $50 \%$ and $100 \%$ coarse RCA, with $25 \%, 35 \%$ and $55 \%$ fly ash as partial cement replacement and exposed to an outdoor environment. Increasing coarse RCA content 


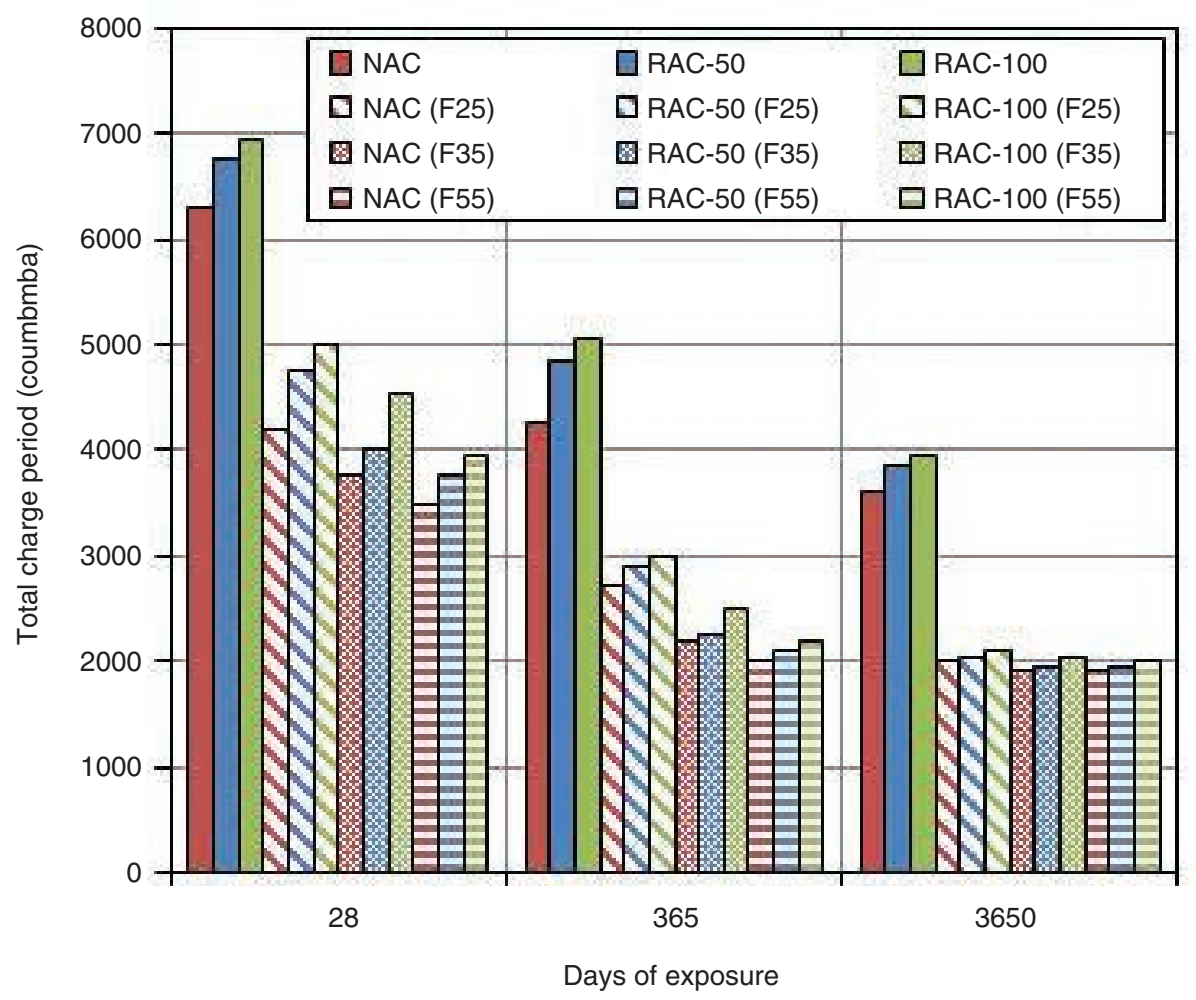

FIGURE 18. Total charge passed of concrete mixes with varying coarse RCA and fly ash content (data sourced from Kou and Poon (119)).

decreased the resistance to chloride ion penetration of the concrete at all test ages. Although the relative difference between the charge passed of concrete mixes with $100 \%$ coarse RCA and that of the corresponding NAC mixes was higher at an initial stage, after 10 years, this relative difference became less than $10 \%$. This means that, regardless of the replacement level, the resistance to chloride ion penetration tends to become similar over the course of time as increasing products of hydration are formed. Figure 18 also shows that replacing cement with increasing fly ash content is an effective approach to reduce the chloride ion penetration. After 28 days, the use of $25 \%, 35 \%$ and $55 \%$ fly ash in specimens with $100 \%$ coarse RCA led to decreases of $28 \%, 33 \%$ and $43 \%$, respectively, when compared to the corresponding specimens without fly ash. After 10 years, regardless of the replacement level, all mixes produced with fly ash exhibited almost 50\% less charge passed than mixes without the mineral addition.

The curing procedure also has a considerable role on the resistance to chloride ion penetration of concrete. Amorin et al. (99) studied the influence of curing conditions on the durability-related properties of concrete mixes with increasing coarse RCA. They reported that subjecting 100\% coarse RCAcontaining specimens to a relatively dry curing environment (i.e. laboratory environment, average
$\mathrm{RH}$ of $60 \%$ and temperature of $20{ }^{\circ} \mathrm{C}$ ) led to an increase of $35 \%$ in the migration coefficient when compared to the control NAC mixes, after a 91-day period. However, this value was just of $23 \%$ when the concrete specimens were cured in a wet chamber. Poon et al. (130) and Kou et al. (131) studied the influence of a steam curing regime to the durability performance of RAC. The authors stated that, after 28 and 90 days, steam-cured specimens showed decreases of about $20 \%$ and $30 \%$, respectively, in the total charge passed, when compared to corresponding specimens subjected to standard curing. The resistance to chloride ion penetration further increased by combining the steam curing regime with the use of fly ash as partial cement replacement; sspecimens containing 35\% fly ash and 100\% coarse RCA presented decreases of $54 \%$ and $72 \%$ in the total charge passed after 28 and 90 days, respectively, when compared to NAC specimens without fly ash and subjected to a standard curing regime.

\subsection{Freeze-thaw resistance}

Some disagreements have been observed concerning the effect of using RCA on the concrete's resistance to freezing and thawing; some suggested decreased resistance of RAC after some freezing and thawing cycles $(113,127,132,133)$, whereas others 
reported negligible difference when compared to NAC $(65,114,134-136)$. These disagreements can be mostly explained by the quality of the RCA, which is often subjective depending on the property under study. In the case of the concrete's resistance to freezing and thawing, the likely shortcomings in the performance of RAC can be attributed to the pore structure of the cementitious microstructure of the source concrete. The use of coarse RCA exhibiting some porosity prompted by the use of airentraining admixtures in the source concrete is likely to result in a RAC with considerable resistance.

Gokce et al. (137) studied the use of different coarse RCA, which were submitted to a varying number of crushing stages (i.e. varying adhered mortar content) and were sourced from airentrained and non-air-entrained concrete products. The factor influencing the performance of RAC, apart from the addition of air-entraining admixtures, was the use of air-entrained RCA; after 500 freezing and thawing cycles, a decline of less than $10 \%$ was observed in the dynamic modulus of elasticity of specimens containing $100 \%$ coarse RCA from an air-entrained concrete. Even though the use of non-air-entrained RCA with lower adhered mortar content appears to have slowed down the decline in the dynamic modulus of elasticity (also supported by the results of Nagataki and Lida (138)), the outcome is insufficient when compared to that obtained from using air-entrained RCA. An assessment to the microstructure showed that the deterioration of RAC started with large cracks in the adhered mortar of the non-air-entrained RCA themselves, causing their disintegration. The presence of these local defects led to load transference to adjacent new mortar, wherein additional propagation of cracking was observed with subsequent freezing and thawing cycles.

Zaharieva et al. (139) observed that, regardless of the adopted production method, in which total and effective w/c ratio varied, RAC exhibited a much faster decline in its properties when compared to a conventional concrete. The main reason for this decline was explained to be due to the high total W/C ratio, which induces greater porosity and poorer mechanical behaviour of RAC, apart from the inherent low resistance to freezing and thawing of the RCA themselves. Similar findings had been observed in the study of Salem et al. (132), in which the reduced resistance to freezing and thawing was found to be due to the additional water existing in the RCA as a result of the saturation. However, the authors observed that this was not the case when air-entraining admixtures were added; RAC with $5 \%$ entrained air exhibited marginal performance loss after 324 freezing and thawing cycles, being comparable to that of the corresponding NAC.

Moon et al. (127) produced RAC using four RCA that had been subjected to different processing stages, resulting in materials with varying adhered mortar contents. The authors observed that the use of RCA with higher adhered mortar content yielded RAC specimens showing a faster decline in the relative dynamic modulus of elasticity with ensuing number of freezing and thawing cycles.

Nagataki and Lida (138) evaluated the influence of the concrete's age on the freezing and thawing resistance. Coarse RCA were obtained from concrete specimens that were crushed after 1 month and 1 year. The authors observed that there was a much faster decline in the relative dynamic modulus of elasticity of RAC using 1-month-old RCA when compared to that made with 1-year-old RCA, the performance of which was comparable to that of the control NAC.

\subsection{Sulphate attack}

Expansion by sulphate attack, which is one of the most deleterious chemical attacks known to occur in concrete, can result from external or internal sources of sulphate. The former is more common and occurs whenever the concrete is subjected to an environment with sulphate containing water (e.g. industrial wastewater). Internal sulphate attack occurs when a source of sulphate is incorporated into the concrete mix, which can be from sulphate-rich aggregates, excessive gypsum in the cement or contamination. The latter gains significant importance in the light of the potentially high gypsum-based contamination of some debris during inadequate construction and demolition operations. It has been observed that RAC containing such RCA are likely to present performance loss due to excessive expansion $(140,141)$.

Dhir et al. (59) studied the resistance to sulphate attack of RAC specimens with increasing coarse RCA content and cured in two different environments. After 18 months of exposure to a sodium sulphate solution, concrete specimens that had been water-cured exhibited length expansions of $0.044 \%$, $0.050 \%, 0.067 \%$ and $0.074 \%$ for replacement levels of $0 \%, 20 \%, 50 \%$ and $100 \%$, respectively. For specimens that had been air-cured, these values were of $0.102 \%, 0.106 \% 0.117 \%$ and $0.134 \%$, respectively, thus showing a decreasing resistance of RAC for increasing replacement levels.

Ridzuan et al. (118) also assessed the resistance to sulphate attack of RAC mixes with increasing coarse RCA content at an air-dry state. As previously explained, using RCA in such a moisture state led to a lower effective w/c ratio and thus higher compressive strength with increasing replacement levels. Similar to that observed in the progression of carbonation, in which equivalent resistance was observed between RAC and NAC, it is possible that there may have been a combination of opposing effects in terms of the resistance to sulphate attack; on the one hand, the decreasing effective w/c ratio 
of the cement paste led to a stronger and denser microstructure; on the other hand, the RCAs' inherent porosity increased the porous network of the resulting RAC. As a result, negligible differences were observed between the expansions of RAC with increasing RCA content and corresponding NAC.

Lee et al. (142)studied the expansion of specimens, containing increasing quantity of RCA exhibiting different water absorption values, subjected to a $5 \%$ sodium sulphate solution. The use of RCA with lower water absorption yielded specimens with enhanced resistance when compared to the use of more porous RCA. This enhanced resistance, nevertheless, was observed for a given ratio of RCA, after which greater expansion started to take place. After 360 days of exposure, specimens made with RCA with a water absorption of $6.6 \%$ at replacement levels of $0 \%, 25 \%, 50 \%, 75 \%$ and $100 \%$ showed expansions of about $0.45 \%, 0.10 \%, 0.25 \%$, $0.37 \%$ and $0.55 \%$, respectively, of the original specimens' size. However, specimens containing RCA, with a water absorption of $10.4 \%$, at replacement levels of $0 \%, 25 \%, 50 \%, 75 \%$ showed expansions of about $0.45 \%, 0.29 \%, 0.29 \%, 0.52 \%$ and $0.55 \%$, respectively, wherein the specimen with $100 \%$ began to disintegrate after 270 days. Similar findings were observed by some of the same authors (143) after having exposed the specimens to sodium and magnesium sulphate solutions for 15 months.

Gokce et al. (137) studied the soundness of coarse RCA, sourced from concrete specimens with different compressive strengths and subjected to varying processing stages, exposed to a sodium sulphate solution. The mass loss of RCA was mainly governed by the adhered mortar content (i.e. lower number of processing stages); RCA with higher adhered mortar content exhibited more mass loss. The aggregates' resistance to sulphate attack was also influenced by the strength of the source concrete; RCA from with higher compressive strength presented less mass loss due to sulphate attack.

\subsection{Alkali-silica reaction}

Alkali-silica reactions are expansive and occur between an alkali solution and silica-based minerals in concrete. The prime source of alkalinity in the mix comes from the cement itself, though any source of sodium or potassium may potentiate the reaction. These reactions occur in the simultaneous presence of sufficient moisture, reactive silica in the aggregates and of alkalis (Neville and Brooks, 2010).

Dhir et al. (144) studied the alkali-silica reaction of mortar samples containing different types of coarse RCA. According to ASTM-C1260 (145), the expansion values for all specimens was under $0.1 \%$, suggesting that the RCA present little reactivity and pose small risk of alkali-silica reaction.
Desmyter and Blockmans (146) reported negligible expansions due to alkali-silica reaction in RAC. The authors reported that the concrete specimens had not reach limit values for expansion beyond which the RCA would be considered as potentially reactive. According to the authors, the reactive constituents present in those RCA would only present a limited reactivity after several years of alkali-silica reaction in a structural concrete.

Etxeberria et al. (147) carried out scanning electron microscopy analysis to RAC and observed the occurrence of alkali-silica reaction after being exposed to a sodium hydroxide solution. Alkalisilica gel developed at the ITZ between the RCA and the new cement. The authors concluded that the potential reactivity of RCA would mostly depend on the siliceous sand present in the old adhered mortar. Nevertheless, negligible expansion or changes in the properties of RAC were observed over time.

\subsection{Resistance to abrasion}

The resistance to abrasion of RAC, in comparison with several other durability-related properties, has not been extensively studied. Existing research on the matter points towards negligible influence or a slight decline in this property with increasing coarse RCA content $(65,148-154)$.

Although control specimens were not produced, Poon and Chan (130) observed that completely recycled paving blocks exhibited an abrasion loss of $16.5 \mathrm{~mm}$, below the $20-\mathrm{mm}$ limit for concrete paving blocks with very good resistance to abrasion (155). In a study published later on (151), the results of paving blocks, completely replaced with RCA, exhibited comparable abrasion resistance to that of the control paving blocks.

The results of Dhir et al. (59) showed that the abrasion of RAC remained mostly unchanged for replacement levels up to $50 \%$ coarse RCA, but showed $34 \%$ greater abrasion depth for specimens with $100 \%$ coarse RCA. Similar findings were reported later on in the study of Fonseca et al. (148), in which the test values for abrasion resistance varied inconsistently for coarse RCA contents up to $50 \%$ without any specific trend. However, all RAC specimens containing 100\% coarse RCA exhibited slightly lower mass loss due to abrasion thereby suggesting improved resistance.

Guerra et al. (156) studied the anchorage of steel rebars in RAC with increasing coarse RCA content. In terms of abrasion resistance, little change was observed in the mass loss of concrete, though slightly lower resistance was observed for $100 \%$ coarse RCA-containing specimens when compared to that of the control (i.e. $3.67 \mathrm{~mm}$ vs $3.52 \mathrm{~mm}$, respectively).

Guneyisi et al. (157) evaluated the effect of incorporating increasing coarse RCA in the properties of 
pervious concrete. An overall decline in performance was observed, including resistance to abrasion. As the replacement level increased, the specimens' depth due to mass loss linearly increased, reaching about $30 \%$ higher when compared to that of the control concrete.

\section{CONCLUSIONS}

This study has critically presented a review on RC's properties including mechanical strengths, strain properties and durability. The main conclusions can be summarized as follows.

RC's properties are influenced by the quality of new and old ITZs. Concrete properties are usually influenced by the weakest one. The recycled aggregate ratio influences strength loss. The lower the recycled aggregate ratio is, the lower the strength loss will be.

According to the analysis of the relationship "RC's compressive strength-conventional concrete's compressive strength", the average reductions are $5 \%, 10 \%$ and $13 \%$ for $20 \%, 50 \%$ and $100 \%$ replacement ratios, respectively. For the relationship between RC and conventional concrete, splitting tensile strength for different replacement ratios, the average reductions were $7 \%$ and $10 \%$ for low $(<50 \%)$ and high ratios $(50-100 \%)$, respectively.

For the time-dependent compressive strength, it can be concluded that RC presents different evolution from conventional concrete. This is due to the internal curing effect provided by the extra water required by recycled aggregate. In this work a new equation was adjusted to this new trend showing that the evolution of RC's compressive strength is especially different at early ages.

The lower the recycled aggregate ratio, the lower the modulus of elasticity loss. For the relationship between RC's and conventional concrete's modulus for different replacement ratios, $50-100 \%$ and $<50 \%$, the average reductions are $11 \%$ and $17 \%$, respectively.

Using multivariable regression and the database of González-Taboada et al. (9), equations to predict the structural RC's modulus of elasticity and splitting tensile strength have been developed. These equations were analysed using the Pearson correlation coefficient and they show a value as good as the best equations in the literature.

Stress-strain curves of RC in compression show the same trend as those of conventional concrete. However, strain increases in RC faster than in conventional concrete, leading to an increase of the curvature of the curves. This fact and the lower modulus of elasticity of RC result in an increase in the peak strain value, which is particularly significant when high replacement ratios are used. In the same way, the tensile peak strain of RC also slightly increases. Regarding the ultimate strain, although there is some scatter in the literature, it seems that it also increases with the replacement ratio. Finally, different models of stress-strain relationship for RC in compression have been proposed.

The use of recycled aggregate leads, in general, to greater deformations due to its higher water absorption and lower hardness than natural aggregates. However, the quality of aggregates is directly related to the shrinkage deformation of concrete. Therefore, the use of high-quality recycled aggregates or different mixing methods may result in $\mathrm{RC}$ with shrinkage deformation similar to that of the conventional concrete, even with high replacement ratios. The mixing of new and old cement mortar also affects the creep behaviour of RC. Hence, since the mortar content is the main factor influencing creep deformation, the higher content of recycled aggregates the greater the creep strain.

Regarding the evolution over time, shrinkage deformation occurs mainly during the first year tending to stabilize over time, both in $\mathrm{RC}$ and conventional concrete. However, RC shows generally a different development at early ages, compared to that of conventional concrete due to internal curing, especially under pre-saturated conditions. This effect results in lower deformations at early ages that grow to a greater extent after this period of internal curing, in terms of both creep and shrinkage.

In terms of code expressions to predict shrinkage deformation, most authors agree that existing models need to be modified in order to consider the influence of different ITZs, old mortar-new mortar and aggregate-old mortar, of recycled aggregates. Finally, using multivariable regression, a modified equation has been proposed to predict concrete shrinkage involving the incorporation ratio of recycled aggregate and the specific behaviour of $\mathrm{RC}$ at early ages. Nevertheless, creep coefficients of RC may be suitably calculated using code expressions except at early age (up to 90 days), where the effect of internal curing should be considered.

From a durability perspective, the increasing incorporation of coarse RCA as replacement for NA leads to an overall increase in porosity of the cementitious microstructure. This causes increased water absorption, progression of carbonation, chloride ion penetration, and decreased resistance to freezing-thawing, to sulphate attack, though negligible effect may be observed in alkali-silica reaction or resistance to abrasion. This general decline in performance varies mostly according to the RCA's adhered mortar, which may vary in content, water absorption, shape and moisture content. RCA that have been subjected to further processing stages are likely to present less adhered mortar content, a more regular shape and, as a result, will yield new concrete products with a closer performance to that of conventional NAC. Sourcing RCA from higher strength concrete products is likely to result 
in denser aggregates, as the original cementitious matrix is less porous than that of concrete typically used in construction. However, RCA with a high strength adhered mortar will have a more beneficial outcome in mechanical properties rather that durability-related ones, especially if it exhibits relatively high porosity. Furthermore, the moisture state of the RCA during the mixing process also has a considerable role in the durability of RAC; incorporating them in a partly dry state and with no compensation of its water absorption is likely to result in a considerable decrease in effective w/c ratio. Although this may bring some benefits in some durability-related properties, it will most certainly affect the retention of workability over time, which would question its applicability in a real scenario.

Although RAC should be more extensively researched in view of its low recognition by professionals in the construction industry, some knowledge gaps stood out the most. In spite of the interesting and practical findings in existing research, three subject matters that should be further developed are the resistance to freezing and thawing, sulphate attack and alkali-silica reaction of RAC. Coarse RCA inherently have a very low resistance to the mechanical stresses induced by continuous freezethaw cycles, unless they are sourced from a concrete product that had been air-entrained. However, from a practical point of view, since it is fairly difficult to distinguish and even segregate air-entrained RCA from non-air-entrained ones, if in sub-zero settings, the use of coarse RCA should be limited to non-structural concrete until acceptable standards can be observed in RAC. In terms of the sulphate attack of RAC, the additional porosity prompted by the incorporation of coarse RCA will likely cause increased mass loss as a result of the greater surface area available to react. However, some factors still need to be researched that may increase the RACs' resistance to these expansive reactions, specifically the presence of some sulphate-resistant phases in the coarse RCAs' adhered mortar or those formed over time as a result of the pozzolanic reactions of mineral additions with the RCA. Furthermore, even though existing research points to little reactivity by coarse RCA due to the presence of potentially reactive siliceous sand in the adhered mortar, alkalisilica reaction in RAC is a broadly understudied subject matter that requires further development.

\section{REFERENCES}

1. United Nations, Sustainable Development Goals(SDGs): 17 goals to transform our world, (2015) 1. https://www.un.org/ sustainabledevelopment/sustainable-development-goals/.

2. Seara-Paz, S.; González-Fonteboa, B.; Martínez-Abella, F.; González-Taboada, I. (2016) Time-dependent behaviour of structural concrete made with recycled coarse aggregates. Creep and shrinkage. Constr. Build. Mater. 122, 95-109. https://doi.org/10.1016/j.conbuildmat.2016.06.050
3. Corinaldesi, V.; Moriconi, G. (2010) Recycling of rubble from building demolition for low-shrinkage concretes. Waste Manag. 30, 655-659. https://doi.org/10.1016/j. wasman.2009.11.026

4. Domingo, A.; Lázaro, C.; Gayarre, F.L.; Serrano, M.A.; López-Colina, C. (2009) Long term deformations by creep and shrinkage in recycled aggregate concrete. Mater. Struct. 43 [8], 1147-1160. https://doi.org/10.1617/ s11527-009-9573-0

5. González-Fonteboa, B.; Martínez-Abella, F.; Herrador, M.F.; Seara-Paz, S. (2012) Structural recycled concrete: Behaviour under low loading rate. Constr. Build. Mater. 28 [1], 111-116. https://doi.org/10.1016/j.conbuildmat. 2011.08 .010

6. Manzi, S.; Mazzotti, C.; Bignozzi, M.C. (2013) Short and long-term behavior of structural concrete with recycled concrete aggregate. Cem. Concr. Compos. 37, 312-318. https://doi.org/10.1016/j.cemconcomp.2013.01.003

7. Corinaldesi, V.; Letelier, V.; Moriconi, G. (2011) Behaviour of beam-column joints made of recycled-aggregate concrete under cyclic loading. Constr. Build. Mater. 25 [4], 18771882. https://doi.org/10.1016/j.conbuildmat.2010.11.072

8. Corinaldesi, V.; Moriconi, G. (2011) The role of industrial by-products in self-compacting concrete. Constr. Build. Mater. 25 [8], 3181-3186. https://doi.org/10.1016/j. conbuildmat.2011.03.001

9. González-Taboada, I.; González-Fonteboa, B.; MartínezAbella, F., Pérez-Ordóñez, J.L. (2013) Prediction of the mechanical properties of structural recycled concrete using multivariable regression and genetic programming. Constr. Build. Mater. 106, 480-499. https://doi.org/10.1016/j. conbuildmat.2015.12.136

10. Kou, S.C.; Poon, C.S.; Wan, H.W. (2012) Properties of concrete prepared with low-grade recycled aggregates. Constr. Build. Mater. 36, 881-889. https://doi.org/10.1016/j. conbuildmat.2012.06.060

11. Mas, B.; Cladera, A.; Del Olmo, T.; Pitarch, F. (2012) Influence of the amount of mixed recycled aggregates on the properties of concrete for non-structural use. Constr. Build. Mater. 27 [1], 612-622. https://doi.org/10.1016/j. conbuildmat.2011.06.073

12. Nealen, A.; Schenk, S. (1998) The influence of recycled aggregate core moisture on freshly mixed and hardened concrete properties. Darmstadt Concr. 13.

13. Ravindrarajah, S.R.; Tam, C.T.; Loo, Y.H. (1987) Recycled concrete as fine and coarse aggregate in concrete. Mag. Concr. Res. 39 [141], 214-220. https://doi.org/10.1680/ macr.1987.39.141.214

14. González-Taboada, I.; González-Fonteboa, B., MartínezAbella, F.; Carro-López, D. (2016) Study of recycled concrete aggregate quality and its relationship with recycled concrete compressive strength using database analysis. Mater. Construcc. 66 [323], e089. https://doi.org/10.3989/ mc. 2016.06415

15. Corinaldesi, V. (2012) Environmentally-friendly bedding mortars for repair of historical buildings. Constr. Build. Mater. 35, 778-784. https://doi.org/10.1016/j. conbuildmat.2012.04.131

16. Nagataki, S.; Gokce, A.; Saeki, T.; Hisada, M. (2004) Assessment of recycling process induced damage sensitivity of recycled concrete aggregates. Cem. Concr. Res. 34 [6], 965-971. https://doi.org/10.1016/j.cemconres.2003.11.008

17. Evangelista, L.; De Brito, J. (2014) Concrete with fine recycled aggregates: A review. Eur. J. Environ. Civ. Eng. 18 [2], 129-172. https://doi.org/10.1080/19648189.2013.851038

18. Otsuki, N.; Miyazato, S.-I.; Yodsudjai, W. (2003) Influence of recycled aggregate on interfacial transition zone, strength, chloride penetration and carbonation of concrete. J. Mater. Civ. Eng. 15 [5], 443-451. https://doi.org/10.1061/ (ASCE)0899-1561(2003)15:5(443)

19. Etxeberria, M.; Vázquez, E.; Marí, A. (2006) Microstructure analysis of hardened recycled aggregate concrete. Mag. Concr. Res. 58 [10], 683-690. https://doi. org/10.1680/macr.2006.58.10.683

20. Xiao, J.; Li, W., Corr, D.J.; Shah, S.P. (2013) Effects of interfacial transition zones on the stress-strain behavior of 
modeled recycled aggregate concrete. Cem. Concr. Res. 52, 82-99. https://doi.org/10.1016/i.cemconres.2013.05.004

21. Pedro, D.; de Brito, J.; Evangelista, L. (2015) Performance of concrete made with aggregates recycled from precasting industry waste: influence of the crushing process. Mater. Struct. 48 [12], 3965-3978. https://doi.org/10.1617/ s11527-014-0456-7

22. Silva, R.V.; De Brito, J.; Dhir, R.K. (2015) The influence of the use of recycled aggregates on the compressive strength of concrete: A review. Eur. J. Environ. Civ. Eng. 19 [7], 825849. https://doi.org/10.1080/19648189.2014.974831

23. Laserna, S.; Montero, J. (2016) Influence of natural aggregates typology on recycled concrete strength properties. Constr. Build. Mater. 115, 78-86. https://doi.org/10.1016/j. conbuildmat.2016.04.037

24. Silva, R. V; Neves, R.; De Brito, J.; Dhir, R.K. (2015) Carbonation behaviour of recycled aggregate concrete. Cem. Concr. Compos. 62, 22-32. https://doi.org/10.1016/j. cemconcomp.2015.04.017

25. Kovler, K.; Roussel, N. (2011) Properties of fresh and hardened concrete. Cem. Concr. Res. 41 [7], 775-792. https:// doi.org/10.1016/j.cemconres.2011.03.009

26. Poon, C.S.; Kou, S.C.; Lam, L. (2007) Influence of recycled aggregate on slump and bleeding of fresh concrete. Mater. Struct. 40 [9], 981-988. https://doi.org/10.1617/ s11527-006-9192-y.

27. Xiao, J.; Li, W.; Fan, Y.; Huang, X. (2012) An overview of study on recycled aggregate concrete in China (1996-2011). Constr. Build. Mater. 31,364-383. https://doi.org/10.1016/j. conbuildmat.2011.12.074

28. Xiao, J.; Li, J.; Zhang, C. (2005) On statistical characteristics of the compressive strength of recycled aggregate concrete. Struct. Concr. 6 [4], 149-153. https://doi.org/10.1680/ stco.2005.6.4.149

29. Pedro, D.; de Brito, J.; Evangelista, L. (2017) Structural concrete with simultaneous incorporation of fine and coarse recycled concrete aggregates: Mechanical, durability and long-term properties. Constr. Build. Mater. 154, 294 309. https://doi.org/10.1016/j.conbuildmat.2017.07.215

30. Rahal, K. (2007) Mechanical properties of concrete with recycled coarse aggregate. Build. Environ. 42 [1], 407-415. https://doi.org/10.1016/j.buildenv.2005.07.033

31. Duan, Z.H.; Kou, S.C.; Poon, C.S. (2013) Using artificial neural networks for predicting the elastic modulus of recycled aggregate concrete. Constr. Build. Mater. 44, 524-532. https://doi.org/10.1016/j.conbuildmat.2013.02.064

32. Park, W.-J, Noguchi, T; Shin, S.-H.; Oh, D.-Y. (2015) Modulus of elasticity of recycled aggregate concrete. Mag. Concr. Res. 67 [11], 585-591. http://doi.org/10.1680/ macr.14.00213

33. Li, X. (2008) Recycling and reuse of waste concrete in China. Part I. Material behaviour of recycled aggregate concrete. Resour. Conserv. Recycl. 53 [1-2], 36-44. https:// doi.org/10.1016/j.resconrec.2008.09.006

34. Zhou, C.; Chen, Z. (2017) Mechanical properties of recycled concrete made with different types of coarse aggregate. Constr. Build. Mater. 134, 497-506. https://doi. org/10.1016/j.conbuildmat.2016.12.163

35. Eiras-López, J.; Seara-Paz, S.; González-Fonteboa, B.; Martínez-Abella, F. (2017) Bond behaviour of recycled concrete. Analysis and prediction of bond stress-slip curve. J. Mater. Civ. Eng. 29 [10]. https://doi.org/10.1061/(ASCE) MT.1943-5533.0002000

36. Corinaldesi, V. (2010) Mechanical and elastic behaviour of concretes made of recycled-concrete coarse aggregates. Constr. Build. Mater. 24 [9], 1616-1620. https://doi. org/10.1016/j.conbuildmat.2010.02.031

37. de Brito, J.; Robles, R. (2010) Recycled aggregate concrete (RAC) methodology for estimating its long-term properties. Indian J. Eng. Mater. Sci. 17 [6], 449-462.

38. Behnood, A.; Olek, J.; Glinicki, M.A. (2015) Predicting modulus elasticity of recycled aggregate concrete using M5' model tree algorithm. Constr. Build. Mater. 94, 137147. https://doi.org/10.1016/j.conbuildmat.2015.06.055

39. Silva, R.V.; De Brito, J.; Dhir, R.K. (2015) Tensile strength behaviour of recycled aggregate concrete. Constr.
Build. Mater. 83, 108-118. https://doi.org/10.1016/j. conbuildmat.2015.03.034

40. Silva, R. V.; De Brito, J.; Dhir, R.K. (2014) Properties and composition of recycled aggregates from construction and demolition waste suitable for concrete production. Constr. Build. Mater. 65, 201-217. https://doi.org/10.1016/j. conbuildmat.2014.04.117

41. Ravindrarajah, S.R.; Tam, C.T. (1985) Properties of concrete made with crushed concrete as coarse aggregate. Mag. Concr. Res. 37 [130]; 29-38. https://doi.org/10.1680/ macr.1985.37.130.29

42. Etxeberria, M.; Marí, A. R.; Vázquez, E. (2007) Recycled aggregate concrete as structural material. Mater. Struct. 40 [5], 529-541. https://doi.org/10.1617/s11527-006-9161-5

43. González-Fonteboa, B.; Martínez-Abella, F.; Carro López, D.; Seara-Paz, S. (2011) Stress-strain relationship in axial compression for concrete using recycled saturated coarse aggregate. Constr. Build. Mater. 25 [5], 2335-2342. https:// doi.org/10.1016/j.conbuildmat.2010.11.031

44. Xiao, J.Z.; Li, J.B.; Zhang, C. (2006) On relationships between the mechanical properties of recycled aggregate concrete: An overview. Mater. Struct. 39 [6], 655-664. https://doi.org/10.1617/s11527-006-9093-0

45. Katz, A. (2003) Properties of concrete made with recycled aggregate from partially hydrated old concrete. Cem. Concr. Res. 33 [5], 703-711. https://doi.org/10.1016/ S0008-8846(02)01033-5

46. Li, J.; Xiao, H. Zhou, Y. (2009) Influence of coating recycled aggregate surface with pozzolanic powder on properties of recycled aggregate concrete Constr. Build. Mater. 23 [3], 1287-1291. https://doi.org/10.1016/j. conbuildmat.2008.07.019

47. Sucic, A. Lotfy, A. (2016) Effect of new paste volume on performance of structural concrete using coarse and granular recycled concrete aggregate of controlled quality. Constr. Build. Mater. 108, 119-128. https://doi. org/10.1016/j.conbuildmat.2015.10.064

48. Malešev, M.; Radonjanin, V.; Marinković, S. (2010) Recycled concrete as aggregate for structural concrete production. Sustainability. 2, 1204-1225. https://doi. org/10.3390/su2051204

49. Ajdukiewicz, A.; Kliszczewicz, A. (2002) Influence of recycled aggregates on mechanical properties of HS/HPC. Cem. Concr. Comp. 24 [2], 269-279. https://doi.org/10.1016/ S0958-9465(01)00012-9

50. Behera, M.; Bhattacharyya, S.K.; Minocha, A.K.; Deoliya, R.; Maiti, S. (2014) Recycled aggregate from C\&D waste \& its use in concrete - A breakthrough towards sustainability in construction sector: A review. Constr. Build. Mater. 68, 501-516. https://doi.org/10.1016/j. conbuildmat.2014.07.003

51. Bairagi, N.K.; Ravande, K.; Pareek, V.K. (1993) Behaviour of concrete with different proportions of natural and recycled aggregates. Resour. Conserv. Recycl. 9 [1-2], 109-126. https://doi.org/10.1016/0921-3449(93)90036-F

52. López, F. (2008) Influencia de la variación de los parámetros de dosificación y fabricación de hormigón reciclado estructural sobre sus propiedades físicas y mecánicas. University of Oviedo (2008).

53. Chakradhara Rao, M.; Bhattacharyya, S.K.; Barai, S. V. (2011) Influence of field recycled coarse aggregate on properties of concrete. Mater. Struct. 44 [1], 205-220. https://doi.org/10.1617/s11527-010-9620-x

54. Padmini, A. K. Ramamurthy, K ; Mathews, M. S. (2009) Influence of parent concrete on the properties of recycled aggregate concrete. Constr. Build. Mater. 23 [2], 829-836. https://doi.org/10.1016/j.conbuildmat.2008.03.006

55. Bhikshma, V.; Kishore, R. (2010) Development of stress strain curves for recycled aggregate concrete. Asian J. Civ. Eng. 11 [2], 253-261.

56. Corinaldesi, V. (2010) Mechanical and elastic behaviour of concretes made of recycled-concrete coarse aggregates. Constr. Build. Mater. 24 [9], 1616-1620. https://doi. org/10.1016/j.conbuildmat.2010.02.031

57. Tangchirapat, W.; Buranasing, R.; Jaturapitakkul, C. (2010) Use of high fineness of fly ash to improve 
properties of recycled aggregate concrete. J. Mater. Civ. Eng. 22 [6], 565-571. https://doi.org/10.1061/(ASCE) MT.1943-5533.0000054

58. Zilch, K.; Roos, F. (2001) An equation to estimate the modulus of elasticity of concrete with recycled aggregates. Civ. Eng. (in Ger) 76, 187-191.

59. Dhir, R.K.; Limbachiya, M.C.; Leelawat, T. (1999) Suitability of recycled concrete aggregate for use in BS 5328 designated mixes. Proc. Inst. Civ. Eng. Struct. Build. 134 [3], 257-274. https://doi.org/10.1680/istbu.1999.31568

60. Mellmann, G. (1999) Processed concrete rubble for the reuse as aggregate. Proc. Int. Semin. Exploit. Waste Concr., $171-178$.

61. KaziKaki, M.; Harada, M., Soshiroda, T., Kubota, S.; Ikeda, T.; Kasai, Y. (1988) Strenght and elastic modulus of recycled aggregate concrete. in: 2nd Int. RILEM Symp. Demolition Reuse Concr. Mason., 565-574.

62. Ravindrarajah, S.R.; Loo, Y.H.; Tam, T. (1987) Recycled concrete as fine and coarse aggregates in concrete. Mag. Concr. Res. 39 [141], 214-220. https://doi.org/10.1680/ macr.1987.39.141.214

63. Ravindrarajah, S.R.; Tam, C.T. (1985) Properties of concrete made with crushed concrete as coarse aggregate. Mag. Concr. Res. 37 [130], 29-38. https://doi.org/10.1680/ macr.1985.37.130.29

64. Dillman, R. (1998) Concrete with recycled concrete aggregate. in: Int. Symp. Sustain. Constr. Use Recycl. Concr. Aggreg., 239-253.

65. Dhir, R.K.; Limbachiya, M.C.; Leelawat, T. (1999) Suitability of recycled concrete aggregate for use in BS 5328 designated mixes. Proc. Inst. Civ. Eng. Struct. Build. 134 [3], 257-274. https://doi.org/10.1680/ istbu. 1999.31568

66. Spanish Ministry of public works. (2008) EHE-08. Regulation of Structural Concrete (In Spanish), Madrid (Spain).

67. European Committee. (2004) Eurocode 2: Design of concrete structure. Brussels (2004).

68. Folino, P.; Xargay, H. (2014) Recycled aggregate concrete - Mechanical behavior under uniaxial and triaxial compression. Constr. Build. Mater. 56, 21-31. https://doi. org/10.1016/j.conbuildmat.2014.01.073

69. Fathifazl, G.; Ghani Razaqpur, A.; Burkan Isgor, O.; Abbas, A.; Fournier, B.; Foo, S. (2011) Creep and drying shrinkage characteristics of concrete produced with coarse recycled concrete aggregate. Cem. Concr. Compos. 33 [10], 1026-1037. https://doi.org/10.1016/j. cemconcomp.2011.08.004

70. Xiao, J.; Li, J.; Zhang, C. (2005) Mechanical properties of recycled aggregate concrete under uniaxial loading. Cem. Concr. Res. 35 [6], 1187-1194. https://doi.org/10.1016/j. cemconres.2004.09.020

71. Yang, H.; Deng, Z.; Ingham, J.M. (2016) Bond position function between corroded reinforcement and recycled aggregate concrete using beam tests. Constr. Build. Mater. 127, 518-526. https://doi.org/10.1016/j. conbuildmat.2016.10.008

72. Du, T.; Wang, W., Liu, Z.; Lin, H.; Guo, T. (2010) The complete stress-strain curve of recycled aggregate concrete under uniaxial compression loading. J. Wuhan Univ. Technol. Mater. Sci. Ed. 25 [5], 862-865. https://doi. org/10.1007/s11595-010-0109-9

73. G, B., Y, M.; J, M. (1978) New material from concrete demolition waste. in: Bibet. Proc. Int. Conf. Use by-Products Waste Civ. Eng., Paris (in French) (1978).

74. Rühl, M.; Atkinson, G. (1999) The influence of recycled aggregate on the stress-strain relation of concrete. Darmstadt Concr. (1999).

75. Liu, Q., Xiao, J.; Sun, Z. (2011) Experimental study on the failure mechanism of recycled concrete. Cem. Concr. Res. 41 [10], 1050-1057. https://doi.org/10.1016/j. cemconres.2011.06.007

76. Holt, E.E. (2001) Early age autogenous shrinkage of concrete. VTT Publ., Finland, 2-184.

77. Sagoe-Crentsil, K.K.; Brown, T.; Taylor, A.H. (2001) Performance of concrete made with commercially produced coarse recycled concrete aggregate. Cem. Concr. Res. 31 [5], 707-712. https://doi.org/10.1016/S0008-8846(00)00476-2

78. Domingo-Cabo, A.; Lázaro, C.; López-Gayarre, F.; Serrano-López, M.A.; Serna, P.; Castaño-Tabares, J.O. (2009) Creep and shrinkage of recycled aggregate concrete. Constr. Build. Mater. 23 [7], 2545-2553. https://doi. org/10.1016/j.conbuildmat.2009.02.018

79. Morohashi, N.; Sakurada, T.; Yanagibashi, K. (2007) Bond splitting strength of high-quality recycled coarse aggregate concrete beams. J. Asian Archit. Build. Eng. 6 [2], 331-337.

80. Brand, A.S.; Roesler, J.R.; Salas, A. (2015) Initial moisture and mixing effects on higher quality recycled coarse aggregate concrete. Constr. Build. Mater. 79, 83-89. https://doi. org/10.1016/j.conbuildmat.2015.01.047

81. Seara-Paz, S.; Corinaldesi, V.; González-Fonteboa, B.; Martínez-Abella, F. (2016) Influence of recycled coarse aggregates characteristics on mechanical properties of structural concrete. Eur. J. Environ. Civ. Eng. 20 [1], s123s139. https://doi.org/10.1080/19648189.2016.1246694

82. Tam, V.W.Y.; Kotrayothar, D.; Xiao, J. (2015) Longterm deformation behaviour of recycled aggregate concrete. Constr. Build. Mater. 100, 262-272. https://doi. org/10.1016/j. conbuildmat 2015.10.013

83. Silva, R.V.; de Brito, J.; Dhir, R.K. (2015) Prediction of the shrinkage behavior of recycled aggregate concrete: A review. Constr. Build. Mater. 77, 327-339. https://doi. org/10.1016/j.conbuildmat.2014.12.102

84. Eckert, M.; Oliveira, M. (2017) Mitigation of the negative effects of recycled aggregate water absorption in concrete technology. Constr. Build. Mater. 133, 416-424. https://doi. org/10.1016/j.conbuildmat.2016.12.132

85. Xiao, J.; Fan, Y.; Tam, V.W.Y. (2015) On creep characteristics of cement paste, mortar and recycled aggregate concrete. Eur. J. Environ. Civ. Eng. 19 [10], 1234-1252. https:// doi.org/10.1080/19648189.2015.1008652

86. Poon, C.S.; Kou, S.C. (2004) Properties of steam cured recycled aggregate concrete. in: Sustain. Waste Manag. Recycl. Constr. Demolition Waste, 1-12.

87. Poon, C.S.; Kou, S.C.; Chan,D. (2006) Influence of steam curing on hardened properties of recycled aggregate concrete. Mag. Concr. Res. 58 [5], 289-299. https://doi. org/10.1680/macr.2006.58.5.289

88. Hanif, A.; Kim, Y.; Lee, K.; Park, C.; Sim, J. (2017) Influence of cement and aggregate type on steam-cured concrete - an experimental study. Mag. Concr. Res. 69 [13], 694-702. https://doi.org/10.1680/jmacr.17.00015

89. Masatao, T; Takafumi, N.: Masaki, T; Manabu, K. Ippei, M.; Hironori, N. (2006) Study of the application of low quality recycled coarse aggregate to concrete structure by surface modification treatment. in: 2nd Asian Concr. Fed. Conf., Bali, Indonesia.

90. Gómez-Soberón, J.M.V. (2002) Porosity of recycled concrete with substitution of recycled concrete aggregate: An experimental study. Cem. Concr. Res. 32 [8], 1301-1311. https://doi.org/10.1016/S0008-8846(02)00795-0

91. Andreu, G.; Miren, E. (2014) Experimental analysis of properties of high performance recycled aggregate concrete. Constr. Build. Mater. 52, 227-235. https://doi. org/10.1016/j.conbuildmat.2013.11.054

92. Butler, L.; West, J.S.; Tighe, S.L. (2013) Effect of recycled concrete coarse aggregate from multiple sources on the hardened properties of concrete with equivalent compressive strength. Constr. Build. Mater. 47, 1292-1301. https:// doi.org/10.1016/j.conbuildmat.2013.05.074

93. Nishibayashi, S.; Yamura, K. (1988) Mechanical properties and durability of concrete from recycled coarse aggregate prepared by crushing concrete. in: Proc. Second Int. RILEM Symp. Demolition Reuse Concr. Masonry, CRC Press, 652-659.

94. Tsujino, M.; Noguchi, T.; Tamura, M.; Kanematsu, M.; Maruyama, I.; Nagai, H. (2006) Study on the application of low-quality coarse aggregate to concrete structure by surface-modification treatment. 2nd Asian Concr. Fed. Conf., Bali, Indonesia (2006), 36-45.

95. Yang, Y.F.; Han, L.H.; Wu, X. (2008) Concrete shrinkage and creep in recycled aggregate concrete-filled 
steel tubes. Adv. Struct. Eng. 11 [4], 383-396. https://doi. org/10.1260/136943308785836772

96. Limbachiya, M.C.; Leelawat, T.; Dhir, R.K. (2000) Use of recycled concrete aggregate in high-strength concrete. Mater. Struct. 33, 574-580. https://doi.org/10.1007/ BF02480538

97. González, B.; Martínez, F. (2004) Shear strength of concrete with recycled aggregates. in: eds. Vázquez $\mathrm{E}$, Hendriks C \& Janssen GMT (Ed.), Int. RILEM Conf. Use Recycl. Mater. Build. Struct., Barcelona, Spain, 619-628. https:// doi.org/10.1007/BF02480538

98. González-Fonteboa, B.; Martínez-Abella, F. (2005) Hormigones con áridos reciclados: estudio de propiedades de los áridos y de las mezclas. Mater. Construcc. 55 [279], 53-66. https://doi.org/10.3989/mc.2005.v55.i279.198

99. Amorim, P.; de Brito, J.; Evangelista, L. (2012) Concrete Made with Coarse Concrete Aggregate: Influence of Curing on Durability. ACI Mater. J. 109 [2], 195-204. https://doi.org/10.14359/51683706

100. Correia, J.R.; de Brito, J.; Pereira, A.S. (2006) Effects on concrete durability of using recycled ceramic aggregates. Mater. Struct. 39 [2], 169-177. https://doi.org/10.1617/ s11527-005-9014-7

101. Buyle-Bodin, F.; Hadjieva-Zaharieva, R. (2002) Influence of industrially produced recycled aggregates on flow properties of concrete. Mater. Struct. Constr. 35 [8], 504-509. https://doi.org/10.1007/BF02483138

102. Ferreira, L.; De Brito, J.; Barra, M. (2011) Influence of the pre-saturation of recycled coarse concrete aggregates on concrete properties. Mag. Concr. Res. 63 [8], 617-627. https://doi.org/10.1680/macr.2011.63.8.617

103. Pedro, D.; De Brito, J.; Evangelista, L. (2014) Influence of the use of recycled concrete aggregates from different sources on structural concrete. Constr. Build. Mater. 71, 141-151. https://doi.org/10.1016/j.conbuildmat.2014.08.030

104. Pedro, D.; De Brito, J.; Evangelista, L. (2017) Evaluation of high-performance concrete with recycled aggregates: Use of densified silica fume as cement replacement. Constr. Build. Mater. 147, 803-814. https://doi. org/10.1016/j.conbuildmat.2017.05.007

105. Padmini, A.K.; Ramamurthy, K.; Mathews, M.S. (2002) Relative moisture movement through recycled aggregate concrete. Mag. Concr. Res. 54 [5], 377-384. https://doi. org/10.1680/macr.2002.54.5.377

106. Matias, D.; de Brito, J.; Rosa, A.; Pedro, D. (2014) Durability of Concrete with Recycled Coarse Aggregates: Influence of Superplasticizers. J. Mater. Civ. Eng. 26 [7], 6014011. https://doi.org/10.1061/(ASCE)MT.1943-5533.0000961

107. Matias, D.; de Brito, J.; Rosa, A.; Pedro, D. (2013) Mechanical properties of concrete produced with recycled coarse aggregates - Influence of the use of superplasticizers. Constr. Build. Mater. 44, 101-109. https://doi. org/10.1016/j.conbuildmat.2013.03.011

108. Tam, V.W.Y.; Gao, X.F.; Tam, C.M. (2005) Microstructural analysis of recycled aggregate concrete produced from twostage mixing approach. Cem. Concr. Res. 35 [6], 1195-1203. https://doi.org/10.1016/j.cemconres.2004.10.025

109. Poon, C.-S.; Chan, D. (2007) Effects of contaminants on the properties of concrete paving blocks prepared with recycled concrete aggregates. Constr. Build. Mater. 21 [1], 164-175. https://doi.org/10.1016/j.conbuildmat.2005.06.031

110. Kou, S.C.; Poon, C.S.; Etxeberria, M. (2011) Influence of recycled aggregates on long term mechanical properties and pore size distribution of concrete. Cem. Concr. Compos. 33 [2], 286-291. https://doi.org/10.1016/j. cemconcomp.2010.10.003

111. Rao, A.; Jha, K.N.; Misra, S. (2007) Use of aggregates from recycled construction and demolition waste in concrete. Resour. Conserv. Recycl. 50 [1], 71-81. https://doi. org/10.1016/j.resconrec.2006.05.010

112. Kikuchi, M.; Yasunaga, A.; Ehara, E. (1993) The total evaluation of recycled aggregate and recycled concrete. in: ed. In: Lauritzen EK (Ed.), Proc. Third Int. RILEM Symp. Demolition Reuse Concr. Mason., Odense, Denmark, 425-436.
113. Kimura, Y.; Imamoto, K.; Nagayama, M.; Tamura, H. (2004) High quality recycled aggregate concrete (HiRAC) processed by decompression and rapid release. in: E. In: Kashino N \& Ohama Y (Ed.), Int. RILEM Symp. Environ. Mater. Syst. Sustain. Dev., College of Engineering, Nihon University, Koriyama, Japan, 163-170.

114. Teranishi, K, Y. Dosho, M. Narikawa, M. Kikuchi, Application of recycled aggregate concrete for structural concrete: Part 3 - Production of recycled aggregate by realscale plant and quality of recycled aggregate concrete. in: E. In: Dhir RK, Henderson NA \& Limbachiya MC (Ed.), Proc. Int. Symp. Sustain. Constr. Use Recycl. Concr. Aggreg., London, UK (1998), 143-156.

115. Ryu, J.S. (2002) An experimental study on the effect of recycled aggregate on concrete properties. Mag. Concr. Res. 54 [1], 7-12. https://doi.org/10.1680/macr.54.1.7.40806

116. Eguchi, K.; Teranishi, K.; Nakagome, A.; Kishimoto, H.; Shinozaki, K.; Narikawa, M. (2007) Application of recycled coarse aggregate by mixture to concrete construction. Constr. Build. Mater. 21 [7], 1542-1551. https://doi. org/10.1016/j.conbuildmat.2005.12.023

117. Dosho, Y. (2007) Development of a Sustainable Concrete Waste Recycling System -Application of Recycled Aggregate Concrete Produced by Aggregate Replacing Method. J. Adv. Concr. Technol. 5 [2], 27-42. https://doi. org/10.3151/jact.5.27

118. Ridzuan, A.; Ibrahim, A.; Ismail, A.; Diah, A. (2005) Durability performance of recycled aggregate concrete. in: E. In: Dhir RK, Dyer TD \& Newlands MD (Ed.) Proc. Int. Conf. Glob. Constr. Ultim. Concr. Oppor. Achiev. Sustain. Constr., London, UK, 193-202.

119. Kou, S.-C.; Poon, C.-S. (2013) Long-term mechanical and durability properties of recycled aggregate concrete prepared with the incorporation of fly ash. Cem. Concr. Compos. 37, 12-19. https://doi.org/10.1016/j. cemconcomp.2012.12.011

120. Silva, R.V.; de Brito, J.; Neves, R.; Dhir, R.; Silva, R.V. (2015) Prediction of Chloride Ion Penetration of Recycled Aggregate Concrete. Mater. Res. 18 [2], 427-440. https:// doi.org/10.1590/1516-1439.000214

121. Tam, V.W.Y.; Tam, C.M. (2007) Assessment of durability of recycled aggregate concrete produced by two-stage mixing approach. J. Mater. Sci. 42 [10], 3592-3602. https://doi. org/10.1007/s10853-006-0379-y

122. Shicong, K.; Poon, C.S. (2006) Compressive strength, pore size distribution and chloride-ion penetration of recycled aggregate concrete incorporating class-F fly ash. J. Wuhan Univ. Technol. Sci. Ed. 21, 130-136. https://doi. org/10.1007/BF02841223

123. Goncalves, A.; Esteves, A - Vieira, M. (2004) Influence of recycled concrete aggregates on concrete durability. in: eds. Vázquez E, Hendriks C \& Janssen GMT (Ed.), Int. RILEM Conf. Use Recycl. Mater. Build. Struct., Barcelona, Spain, 554-562.

124. Kou, S.C.; Poon, C.S.; Dixon, C. (2007) Influence of fly ash as cement replacement on the properties of recycled aggregate concrete. J. Mater. Civ. Eng. 19 [9], 709-711. https:// doi.org/10.1061/(ASCE)0899-1561(2007)19:9(709)

125. Kou, S.; Poon, C.; Lam, L.; Chan, D. (2004) Hardened properties of recycled aggregate concrete prepared with fly ash. in: eds. In: Limbachiya MC \& Roberts JJ (Ed.), Proc. Int. Conf. Sustain. Waste Manag. Recycl. Challenges Oppor., London, UK, 189-197.

126. Kou, S.; Poon, C.; Agrela, F. (2011) Comparisons of natural and recycled aggregate concretes prepared with the addition of different mineral admixtures. Cem. Concr. Compos. 33 [8], 788-795. https://doi.org/10.1016/j. cemconcomp 2011.05.009

127. Moon, D.; Moon, H.; Nagataki, S.; Hisada, M.; Saeki, T. (2002) Improvement on the qualities of recycled aggregate concrete containing super fine mineral admixtures in: E. In: Kyokai PK \& Kyokai NK (Ed.), Proc. 1st Fib Congr., Osaka, Japan, 113-118.

128. Ann, K.Y.; Moon, H.Y.; Kim, Y.B.; Ryou, J. (2008) Durability of recycled aggregate concrete using 
pozzolanic materials. Waste Manag. 28, 993-999. https:// doi.org/10.1016/j.wasman.2007.03.003

129. Berndt, M.L. (2009) Properties of sustainable concrete containing fly ash, slag and recycled concrete aggregate. Constr. Build. Mater. 23 [7], 2606-2613. https://doi. org/10.1016/j.conbuildmat.2009.02.011

130. Poon, C.S.; Chan, D. (2006) Paving blocks made with recycled concrete aggregate and crushed clay brick. Constr. Build. Mater. 20 [8], 569-577. https://doi.org/10.1016/j. conbuildmat.2005.01.044

131. Kou, S.; Poon, C.; Chan, D. (2004) Properties of steam cured recycled aggregate fly ash concrete. in: E. In: Vázquez E, Hendriks C \& Janssen GMT (Ed.), Int. RILEM Conf. Use Recycl. Mater. Build. Struct., Barcelona, Spain, 590-599.

132. Salem, R.M.; Burdette, E.G.; Jackson, N.M. (2003) Resistance to freezing and thawing of recycled aggregate concrete. ACI Mater. J. 100 [3], 216-221. https://doi. org/10.14359/12622

133. Yanagibashi, K.; Yonezawa, T.; Arakawa, K.; Yamada, M. (2002) A new concrete recycling technique for coarse aggregate regeneration process. in: eds. In: Dhir RK, Dyer TD \& Halliday JE (Ed.), Proc. Int. Conf. Sustain. Concr. Constr., Scotland, UK, 511-522. https://doi.org/10.1680/ scc.31777.0052

134. Merlet, J.; Pimienta, P. (1993) Mechanical and physicochemical properties of concrete produced with coarse and fine recycled concrete aggregates. in: E. In: Lauritzen EK (Ed.), Proc. Third Int. RILEM Symp. Demolition Reuse Concr. Mason., Odense, Denmark, 400-411.

135. Van Acker, A. (1998) Recycling of concrete at a precast concrete plant. in: E. In: Dhir RK, Henderson NA \& Limbachiya MC (Ed.), Proc. Int. Symp. Sustain. Constr. Use Recycl. Concr. Aggreg., London, UK, 321-332.

136. Hosokawa, Y. (1999) Concrete products using fine aggregate recycled from waste concrete products. in: 8th Int. Conf. Durab. Build. Mater. Components, In: Lacasse MA \& Vainer DJ, Otawa, canada, 475-484.

137. Gokce, A.; Nagataki, S.; Saeki, T.; Hisada, M. (2004) Freezing and thawing resistance of air-entrained concrete incorporating recycled coarse aggregate: The role of air content in demolished concrete. Cem. Concr. Res. 34 [5], 799-806. https://doi.org/10.1016/j.cemconres.2003.09.014

138. Nagataki, S.; Lida, K. (2001) Recycling of demolished concrete. in: E. In: Malhotra VM (Ed.), Fifth CANMET/ACI Int. Conf. Recent Adv. Concr. Technol., Singapore, 1-20.

139. Zaharieva, R.; Buyle-Bodin, R.; Wirquin, E. (2004) Frost resistance of recycled aggregate concrete. Cem. Concr. Res. 34 [10], 1927-1932. https://doi.org/10.1016/j. cemconres. 2004.02.025

140. Al-Attar, T.S.; Al-Khateeb, A.M.; Bachai, A.H. (2006) Behavior of High Performance Concrete Exposed to Internal Sulfate Attack (Gypsum-Contaminated Aggregate). in: Earth \&amp; Sp. 2006, American Society of Civil Engineers, Reston, VA, 1-6. https://doi. org/10.1061/40830(188)161

141. Tovar-Rodríguez, G.; Barra, M.; Pialarissi, S.; Aponte, D.; Vázquez, E. (2013) Expansion of mortars with gypsum contaminated fine recycled aggregates. Constr. Build. Mater. 38, 1211-1220. https://doi.org/10.1016/j. conbuildmat.2012.09.059

142. Lee, S.T.; Moon, H.Y.; Swamy, R.N.; Kim, S.S.; Kim, J.P. (2005) Sulfate Attack of Mortars Containing Recycled
Fine Aggregates. ACI Mater. J. 102 [4], 224-230. https:// doi.org/10.14359/14614

143. Lee, S.-T.; Swamy, R.N.; Kim, S.-S.; Park, Y.-G. (2008) Durability of Mortars Made with Recycled Fine Aggregates Exposed to Sulfate Solutions. J. Mater. Civ. Eng. 20 [1], 63-70. https://doi.org/10.1061/ (ASCE)0899-1561(2008)20:1(63)

144. Dhir, R.; McCarthy, M.; Halliday, J.; Tang, M. (2005) ASR testing on recycled aggregates guidance on alkali limits and reactivity.

145. ASTM-C1260 (2014) Standard test method for potential alkali reactivity of aggregates (mortar-bar method), $5 \mathrm{p}$.

146. Desmyter, J.; Blockmans, S. (2000) Evaluation of different measures to reduce the risk of alkali silica reaction in recycled aggregate concrete. in: Proc. 11th Int. Conf. AlkaliAggregate React. Concr. Canada, 603-612.

147. Etxeberria, M.; Vázquez, E.; Vázquez, E. (2010) Reacción álcali sílice en el hormigón debido al mortero adherido del árido reciclado. Mater. Construcc. 60 [297], 47-58. https:// doi.org/10.3989/mc.2010.46508

148. Fonseca, N.; de Brito, J.; Evangelista, L. (2011) The influence of curing conditions on the mechanical performance of concrete made with recycled concrete waste. Cem. Concr. Compos. 33 [6], 637-643. https://doi.org/10.1016/j. cemconcomp.2011.04.002

149. Lotfi, S.; Deja, J.; Rem, P.; Mróz, R.; van Roekel, E.; van der Stelt, H. (2014) Mechanical recycling of EOL concrete into high-grade aggregates. Resour. Conserv. Recycl. 87, 117-125. https://doi.org/10.1016/j.resconrec.2014.03.010

150. Lotfi, S.; Eggimann, M.; Wagner, E.; Mróz, R.; Deja, J. (2015) Performance of recycled aggregate concrete based on a new concrete recycling technology. Constr. Build. Mater. 95, 243-256. https://doi.org/10.1016/j. conbuildmat.2015.07.021

151. Poon, C.S.; Lam, C.S. (2008) The effect of aggregate-tocement ratio and types of aggregates on the properties of pre-cast concrete blocks. Cem. Concr. Compos. 30 [4], 283289. https://doi.org/10.1016/j.cemconcomp.2007.10.005

152. Soares, D.; de Brito, J.; Ferreira, J.; Pacheco, J. (2014) Use of coarse recycled aggregates from precast concrete rejects: Mechanical and durability performance. Constr. Build. Mater. 71, 263-272. https://doi.org/10.1016/j. conbuildmat.2014.08.034

153. Sadati, S.; Khayat, K.H. (2016) Field performance of concrete pavement incorporating recycled concrete aggregate. Constr. Build. Mater. 126, 691-700. https://doi. org/10.1016/j.conbuildmat.2016.09.087

154. Zaetang, Y.; Sata, V.; Wongsa, A., Chindaprasirt, P. (2016) Properties of pervious concrete containing recycled concrete block aggregate and recycled concrete aggregate. Constr. Build. Mater. 111, 15-21. https://doi.org/10.1016/j. conbuildmat.2016.02.060

155. EN-1338 (2003) Concrete paving blocks - Requirements and test methods, $76 \mathrm{p}$.

156. Guerra, M.; Ceia, F.; De Brito, J.; Júlio, E. (2014) Anchorage of steel rebars to recycled aggregates concrete. Constr. Build. Mater. 72, 113-123. https://doi.org/10.1016/j. conbuildmat.2014.08.081

157. Güneyisi, E.; Gesoğlu, M.; Kareem, Q.; İpek, S. (2016) Effect of different substitution of natural aggregate by recycled aggregate on performance characteristics of pervious concrete. Mater. Struct. 49 [1-2], 521-536. https://doi. org/10.1617/s11527-014-0517-y 